\title{
LAWS OF TURBULENT FLOW IN OPEN CHANNELS
}

\author{
By Garbis H. Keulegan
}

\section{ABSTRACT}

The theoretical investigations of Prandtl and Kármán, and the experimental work of Nikuradse, have led to rational formulas for velocity distribution and hydraulic resistance for turbulent flow in circular pipes. With certain assumptions regarding the effects of secondary currents and of the free surface, and with the adoption of the hydraulic radius as the characteristic length, similar rational formulas are deduced for open channels. The validity and the applications of these formulas are illustrated by a study of Bazin's experiments. In this study the equivalent sand roughnesses of the channels used by Bazin are determined. The criterion for determining the conditions under which a channel with woodenplank surfaces is to be considered hydrodynamically wavy or hydrodynamically rough is also evaluated. The rational formulas with constants determined from Bazin's experiments are expressed in the form of power laws. It is shown that Manning's empirical formula is a good approximation to the rational formula for rough channels when the relative roughness is large.

\section{CONTENTS}

I. Introduction

II. Development of the theory

1. Kármán law of velocity distribution

(a) General law of velocity distribution near a solid wall.

(b) General equation of velocity distribution for smooth walls

(c) General equation of velocity distribution for wavy walls _................

(d) General equation of velocity distribution for rough walls

2. Derivation of resistance formulas

(a) Resistance formulas for circular and infinitely wide
rectangular pipes.

(1) Smooth walls

(2) Rough walls

(b) Resistance formulas for channels with polygonal cross sections . .

(1) Trapezoidal channels

(2) Channels of other shapes .

(3) Error from neglect of the correction terms

(c) Equivalent sand roughness

III. Application to Bazin's experimental data .............

1. Description of Bazin's channel installation

2. Equivalent sand roughness for some of Bazin's channels ..... 724

3. Surfaces of wood as examples of waviness _............. 727

4. Effect of shape of cross section on mean velocity

5. Distribution of velocity in rough channels $\ldots$

6. Maximum velocity in rough rectangular channels

IV. Manning's formula for rough channels-power-law formulas _...... 737

V. References 


\section{INTRODUCTION}

The theoretical investigations of the phenomena of turbulent flow by Prandtl and by Kármán have prepared the way for rational interpretations of experimental results. In these investigations two distinct relationships of basic importance are expressed. First, in a unidirectional turbulent flow the apparent shear at any point depends on the square of the velocity gradient at that point. Second, the factor of proportionality in the relation of the apparent shear to the square of the velocity gradient is determinate once the similarity of turbulence is assumed. As a result of these two relationships, not only the velocity distribution, but also the hydraulic resistance factor for circular pipes, has been expressed in a rational form; that is, in a form derived by analytical methods involving only two constants to be determined by experiments. One of these constants is a universal constant, which is a characteristic of turbulence. The other constant is a characteristic of the surface of the pipe, which will be called the "surface characteristic" in this paper. In his classic experiments on circular pipes, Nikuradse $[1,2]^{1}$ determined the universal constant of turbulence and the surface characteristics for smooth pipes and for pipes with one type of rough surface. These general results are well known and are presented in detail in recent works [3].

This paper is an attempt to apply these same principles to the problem of turbulent flow in open channels, mainly for the purpose of developing formulas for resistance or for mean flow in forms similar to those obtained for circular pipes. Two assumptions are made in developing the formulas. The first assumption is that Kármán's universal law of velocity distribution near a solid boundary is of general applicability. The second assumption is one in regard to the effects of secondary currents and of the free surface. It is assumed that the average result of these effects over the cross section of a channel is, in general, a small quantity which can be merged in the surface characteristics entering the flow formulas. Furthermore, it is found that when the hydraulic radius is adopted as the characteristic length of a channel cross section, the resulting formulas become practically independent of the shape of the channel except for a correction of geometrical origin which can likewise be merged with the surface characteristic. Thus the formulas for flow in open channels are identical in form with those for flow in circular pipes, the differences being in the values of the surface characteristics.

The necessary experimental data used in this paper are taken exclusively from Bazin's pioneer research [4] on flow in open channels, which constitutes an outstanding monument to early scientific work in this field. These experiments were carried out on a large scale near Dijon, France, in the years 1855 to 1860.

As a matter of convenience, the following definitions are adopted. A "pipe" is a conduit for carrying water in which the flowing stream is entirely bounded by solid surfaces. A "channel" is a conduit for carrying water in which the flowing stream is in part bounded by an air surface; that is, the stream has a free surface. The word "channel" is thus used as a synonym for the expression "open channel."

\footnotetext{
${ }_{1}$ Figures in brackets indicate the literature references at the end of this paper.
} 


\section{DEVELOPMENT OF THE THEORY}

\section{THE KĀRMĀN LAW OF VELOCITY DISTRIBUTION}

The discussion here of the theory of velocity distribution relates to unidirectional flow in the neighborhood of a plane wall of large extent. When it is necessary to consider experiments for verification of the theoretical results, reference will be made to studies of flow in circular pipes, since numerous and reliable data are available for this case. These references are permissible because the flow in circular pipes is also unidirectional.

Again, in these discussions the thin laminar layer at the wall will be ignored, since the portion that it contributes to the total flow is negligible.

(a) GENERAL LAW OF VELOCITY DISTRIBUTION NEAR A SOLID WALL

Prandtl [5] has given the following expression for the turbulent shear stress at any point in a fluid moving past a solid wall (see fig. 1):

where

$$
\sqrt{\tau / \rho}=l \frac{d u}{d y}
$$

$\tau=$ the shearing stress at the point,

$\rho=$ the density of the fluid,

$u=$ the velocity at the point,

$y=$ the distance of the point from the wall, and

$l=$ the so-called mixing length of momentum exchange.

For the purpose of finding an approximate law of velocity distribution in the neighborhood of the wall, we write eg 1 in the form

$$
\sqrt{\tau_{0} / \rho}=l \frac{d u}{d y} \sqrt{\tau_{0} / \tau}
$$

where $\tau_{0}$ is the shear in the fluid at the wall.

The quantity in the left member of eq 2 has the dimensions of a velocity, and, because of its significance, has been called by Prandtl the shear velocity, denoted by the symbol $u_{*}$. To make the concept of shear velocity more concrete, it may be pointed out that it can be expressed in the following simple manner in terms of more customarily used quantities:

$$
u_{*}=\sqrt{R i g},
$$

both for flow in circular pipes and

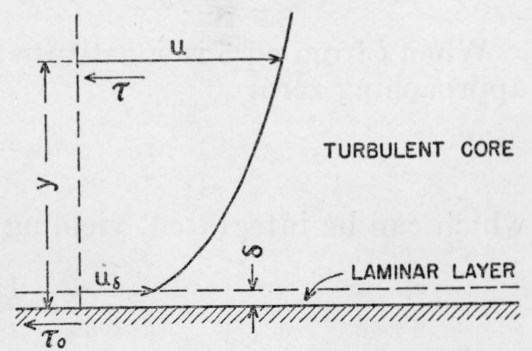

FIGURE 1.-Diagram of velocity distribution in a stream flowing past a solid wall to illustrate notation.

for uniform flow in wide channels, where

$R=$ the hydraulic radius,

$i=$ the hydraulic gradient, and

$g=$ the acceleration of gravity.

Introducing the notation for the shear velocity, we write eq 2 as

$$
u_{*}=l \frac{d u}{d y}\left(\frac{\tau_{0}}{\tau}\right)^{1 / 2} .
$$


As a consequence of his principle of similarity of turbulence, Kármán derived the following expression for the mixing length $l$ at any point $y$ in terms of the velocity gradient at $y$ :

$$
l=\kappa \frac{u^{\prime}}{u^{\prime \prime}},
$$

where the primes indicate differentiation with respect to $y$, and $\kappa$ is a universal constant characterizing the turbulence [5]. This latter expression for $l$, however, requires a modification for the following reason. The two experimental determinations of $l$ from the independent expressions, eq 4 and 5, using the velocity measurements in smooth or rough circular pipes, may be made to agree with each other for small values of $y$ by selecting $\kappa$ properly. But, then, for the same value of $\kappa$ the two values of $l$ show gradually increasing differences for increasing $y$, the largest difference occurring for $y=y_{m}, y_{m}$ being the wall distance corresponding to $\tau=0$ [1]. Obviously, the agreement between the two determinations would be improved if now we select in the place of eq 5 ,

$$
l=\kappa\left|\frac{u^{\prime}}{u^{\prime \prime}}\right|\left[1+k_{1} \frac{y}{y_{m}}+k_{2}\left(\frac{y}{y_{m}}\right)^{2}+\ldots .\right],
$$

where $k_{1}$ and $k_{2}$ are constants.

Since in the types of flows we shall be considering, the component of acceleration normal to the direction of mean flow would be negligible,

$$
\tau=\tau_{0}\left(1-y / y_{m}\right),
$$

eq 4 then may be written also as

$$
u_{*}=l \frac{d u}{d y}\left[1+\frac{1}{2} \frac{y}{y_{m}}+\frac{3}{8}\left(\frac{y}{y_{m}}\right)^{2}+\ldots .\right] .
$$

When $l$ from eq 5 is substituted in eq 4 there results, for values of $y$ approaching zero,

$$
u_{*}=\kappa \frac{\left(u^{\prime}\right)^{2}}{u^{\prime \prime}},
$$

which can be integrated, yielding

$$
\frac{u}{u_{*}}=\frac{1}{\kappa} \ln \left(y / y_{0}\right),
$$

where $y_{0}$ is a constant of integration. The other constant resulting from the first integration of eq 6 is put equal to zero as the consequence of the limiting value of $u^{\prime}$ at the wall. This is Kármán's law of velocity distribution in the neighborhood of a solid wall. The derivation is made for small values of $y$. Experience, on the other hand, shows that eq 7 is sufficiently accurate also for large values of $y$, even when $y$ is as large as $y_{m}$. In the second approximate solution, the differential equation corresponding to eq 6 would contain $y / y_{m}$. The form of the resulting equation is necessarily complex and hardly suitable for the usual computations. Equation 7, being of a simpler form and also sufficiently accurate, will serve as the basis for the elementary mathematical development of this paper. 
Theoretical considerations indicate that $\kappa$ should be independent of the nature of the wall surface. This has been verified in the cases of flow in circular pipes and between parallel walls [6]. On the other hand, the constant of integration $y_{0}$, a length that we may term the "characteristic length of turbulence," varies with the shear velocity, and the roughness of the wall.

The next step is to consider the evaluation of $y_{0}$. Let $\delta$ be the minimum distance from the wall at which eq 7 holds. (See fig. 1.) That is, $\delta$ is the thickness of the boundary layer in which the viscous stresses either predominate or are of the same order as the apparent stresses due to momentum exchange. It can be shown easily that the rate of energy dissipation $E$ in this layer per unit of surface is

$$
E=\tau_{0} u_{\delta}
$$

where $u_{\delta}$ is the velocity for $\mathrm{y}=\delta$. From eq 7 :

$$
u_{\delta} / u_{*}=(1 / \kappa) \ln \left(\delta / y_{0}\right),
$$

and eliminating $u_{\delta}$ from the last two equations:

$$
\ln \left(\frac{y_{0}}{\delta}\right)=-\frac{\kappa E}{\rho u_{*}{ }^{3}}
$$

Unfortunately, in the present state of our knowledge of turbulence $E$ and $\delta$ cannot be computed, so that eq 9 does not serve as a means of computing $y_{0}$.

In the absence of an adequate theory, the natural procedure is to resort to experience, using the method of dimensional reasoning as a guide. Based on the hydrodynamical effects that they produce, solid boundaries are usually classified as smooth, wavy, or rough. For these three types of walls, $y_{0}$ may be expressed in three distinct forms which will now be developed.

(b) GENERAL EQUATION OF VELOCITY DISTRIBUTION FOR SMOOTH WALLS

If the surface of the wall is smooth, $y_{0}$ will depend solely on $u_{*}$ and $\nu$, and dimensional reasoning then furnishes the relation

where

$$
\frac{y_{0} u_{*}}{\nu}=m
$$

$m=a$ constant, and

$\nu=$ the kinematic viscosity.

Substitution of this value of $y_{0}$ in eq 7 yields

$$
\left.\begin{array}{rl}
\frac{u}{u_{*}} & =a_{s}+\frac{1}{\kappa} \ln \left(\frac{y u_{*}}{\nu}\right) \text {, or } \\
\frac{u}{u_{*}} & =a_{s}+\frac{2.30}{\kappa} \log \left(\frac{y u_{*}}{\nu}\right),
\end{array}\right\}
$$


which is the universal law of velocity distribution in the neighborhood of a smooth wall. The relation between the constants $a_{s}$ and $m$ is

$$
a_{s}=\frac{1}{\kappa} \ln \left(\frac{1}{m}\right),
$$

which may also be written in the form

$$
m=e^{-\kappa a} \text {. }
$$

The law expressed by eq 11 has been confirmed by Nikuradse [1], who obtained from experiments on smooth pipes the relation

$$
\frac{u}{u_{*}}=5.5+5.75 \log \left(\frac{y u_{*}}{\nu}\right)
$$

Comparison of the experimentally determined values in eq 13 with the corresponding algebraic expressions in eq 11 gives

$$
\kappa=0.40 \text { and } y_{0}=\frac{1}{9} \frac{\nu}{u_{*}} .
$$

This value of $y_{0}$ was first given by Prandtl.

Kármán gives for $\delta$ the experimentally determined value

$$
\delta=11.5 \frac{\nu}{u_{*}} .
$$

(c) GENERAL EQUATION OF VELOCITY DISTRIBUTION FOR WAVY WALLS

When the wall surface is smooth but wavy in character (see fig. 2)

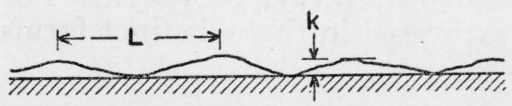

WAVY SURFACE

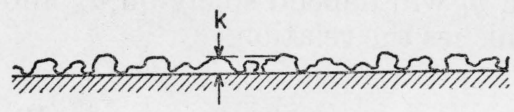

ROUGH SURFACE

FigURe 2.-Diagrams of wavy and rough surfaces. and the wall shear is sufficiently low, $y_{0}$ is given by a relation of the form

$$
\frac{y_{0} u_{*}}{\nu}=f\left(\frac{k}{L}\right)
$$

where

$L=$ the length of a wave, and $k=$ the height of a wave.

The ratio $k / L$ may be called the "relative waviness." For a given ratio $k / L$, the function $f$ may vary with the shape of the wavy projections, and hence surfaces with waves of different shapes must be treated separately.

If we introduce in eq 7 the value of $y_{0}$ from eq 16 , there results

$$
\left.\begin{array}{rl}
\frac{u}{u_{*}} & =a_{w}+\frac{1}{\kappa} \ln \left(\frac{y u_{*}}{\nu}\right), \text { or } \\
\frac{u}{u_{*}} & =a_{w}+\frac{2.30}{\kappa} \log \left(\frac{y u_{*}}{\nu}\right) .
\end{array}\right\}
$$


This is the universal law of velocity distribution for wavy surfaces. The relation between $a_{w}$ and the relative waviness is given by

$$
f\left(\frac{k}{L}\right)=e^{-\kappa a_{w}}
$$

Our present very meager knowledge of wavy surfaces may be summarized by the statement that $a_{w}$ decreases as $k / L$ increases.

(d) GENERAL EQUATION OF VELOCITY DISTRIBUTION FOR ROUGH WALLS

When the wall surface is rough (see fig. 2), the expression for $y_{0}$ must be derived from $k$, the elevation of the roughness elements. The theory of dimensions then yields the relation

$$
\frac{y_{0} u_{*}}{\nu}=f\left(\frac{k u_{*}}{\nu}\right),
$$

and accordingly the velocity distribution is given by substituting the value of $y_{0}$ thus obtained in eq 7 :

$$
\left.\begin{array}{c}
\frac{u}{u_{*}}=a_{\tau}+\frac{1}{\kappa} \ln \left(\frac{y u_{*}}{\nu}\right), \text { or } \\
\frac{u}{u_{*}}=a_{r}+\frac{2.30}{\kappa} \log \left(\frac{y u_{*}}{\nu}\right) .
\end{array}\right\}
$$

This is the universal law of velocity distribution for rough surfaces.

The relation between $a_{r}$ and the Reynolds number based on the height of the roughness elements is

$$
f\left(\frac{k u_{*}}{\nu}\right)=e^{-\kappa a_{r}} .
$$

The function $f$ is known completely only for roughness produced by closely packed grains of sand, as determined by Nikuradse [2] by experiments on pipes of circular cross section. For the roughness of surfaces of the type used by Nikuradse, the symbol $k_{s}$ will be adopted, to represent the mean height of the sand grains forming the roughness elements.

Nikuradse's data are given in figure 3 , in which $a_{r}$ is plotted as ordinate against $\log \left(k_{s} u_{*} / \nu\right)$ as abscissa. Figure 3 shows that, when $k_{s} u_{*} / \nu$ is less than about $3.3, a_{r}$ is independent of $u_{*}$ and has the value 5.5 , which is the value of $a_{s}$ for smooth surfaces. In other words, when $u_{*}<3.3 \nu / k_{s}$, the surface behaves as if it were smooth.

Figure 3 also shows that when $k_{s} u_{*} / \nu$ is greater than about $67, a_{r}$ is given by the expression.

$$
a_{r}=8.5-2.5 \ln \left(\frac{k_{s} u_{*}}{\nu}\right)=8.5-5.75 \log \left(\frac{k_{s} u_{*}}{\nu}\right) .
$$

Substitution of this result in eq 20 gives

$$
\frac{u}{u_{*}}=8.5+5.75 \log \left(\frac{y}{k_{s}}\right),
$$


which is the law of velocity distribution in the vicinity of a surface covered with closely packed sand grains. Since the viscosity of the fluid does not enter eq 23, the equation applies to flow in the region where the hydraulic resistance varies with the square of the mean velocity.

The significant point of Nikuradse's investigation is the establishment of these two critical numbers for rough surfaces : $\left(k_{s} u_{*} / \nu\right)_{1}=3.3$ and $\left(k_{s} u_{*} / \nu\right)_{2}=67$. These critical numbers define a transition region in which both the kinematic viscosity and the relative roughness affect the friction. The complete generality of the results of Niku-

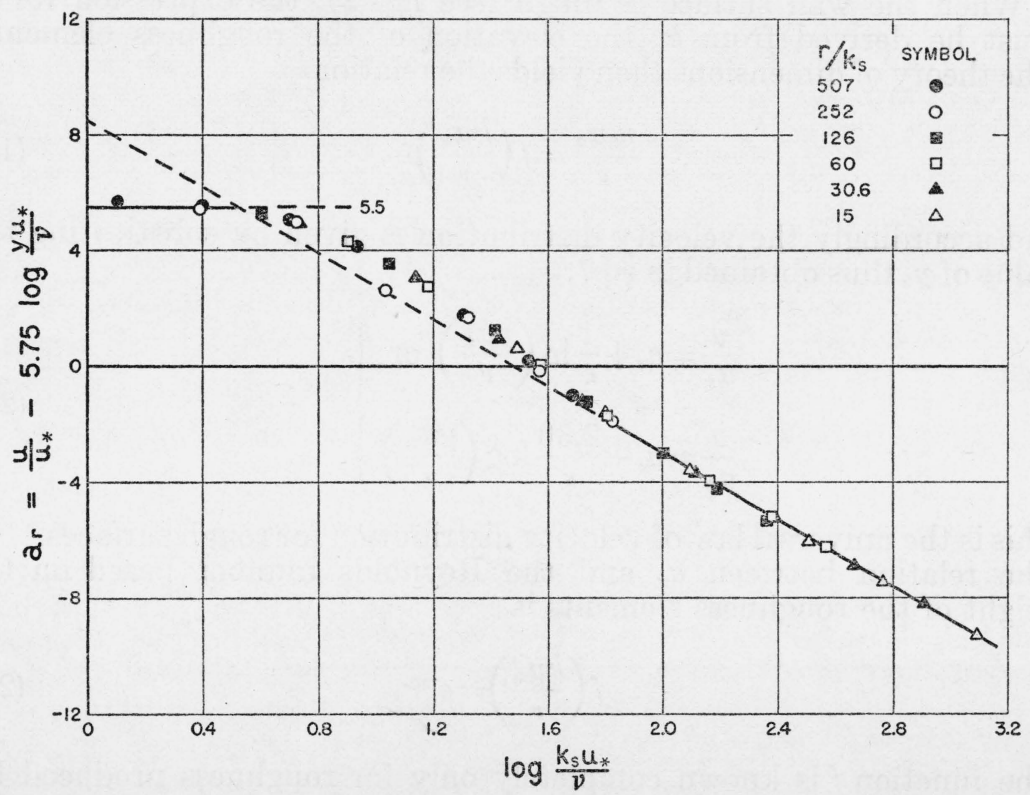

FIGURE 3.-Surface characteristic $a_{r}$ as a function of $\log \left(k_{s} u_{*} / \nu\right)$ for circular pipes with surfaces of closely packed sand grains, according to Nikuradse.

radse's investigation has been questioned on the grounds that the pipes which he used were not long enough. If this claim is valid, then we may expect to find lower values for the criteria if very long pipes are used, the effect being more pronounced for the higher critical number.

Schlichting's investigation [7] of roughness consisting of regular geometrical forms having a preassigned distribution has shown that in this case the velocity distribution law in the region where the quadratic resistance law holds is given by

$$
\frac{u}{u_{*}}=a_{r 0}+5.75 \log \left(\frac{y}{k}\right),
$$

which is of the same form as eq 23. Here $a_{r 0}$ varies both with the shape and distribution of the roughness elements.

Thus the significant deduction to be derived from the resulte of experiments with rough surfaces in the region where the quadratic resistance law holds is that $a_{r}$ in eq 20 satisfies the relation 


$$
a_{r}=a_{r 0}-\frac{1}{\kappa} \ln \left(\frac{k u_{*}}{\nu}\right),
$$

where $a_{r 0}$ has different values depending on the shape and distribution of the roughness elements of the surface under consideration, For a surface covered with sand $a_{r 0}=8.5$.

Presumably wavy surfaces will also behave like rough surfaces if the velocity is high enough. The few investigations of wavy surfaces reported in the literature have involved relatively low velocities, and the results indicate that the resistance is independent of the relative roughness for such velocities. However, it seems reasonable to assume that, if the velocity is increased sufficiently, the conditions in the boundary layer will be changed so as to produce a resistance that will vary with the square of the velocity. This condition will exist for wall shears given by the inequality

$$
\left(u_{*} k / v\right)>\phi\left(u_{*} L / v\right),
$$

where $\phi$ is a function to be determined. When eq 26 is satisfied, then the velocity distribution for a wavy surface will be given by eq 20 .

The constants $a_{s}, a_{w}, a_{r}$, and $a_{r 0}$ will be referred to hereafter in this paper as the "hydraulic characteristics of the surfaces," or more briefly, the "surface characteristics."

\section{DERIVATION OF RESISTANCE FORMULAS}

Careful experiments have shown that the resistance coefficient in pipes for a given Reynolds number $R_{e}$ is not affected by the shape of the pipe, provided that in forming the Reynolds number the hydraulic radius $R$ is used as the characteristic length of the pipe [8]. This can be explained by assuming that turbulent flow exhibits the following two properties. First, the velocity at a point in the vicinity of a wall depends solely on the shear at the wall element nearest to the point and not on the shear over the whole wall surface. Secondly, when the distance of the point from the wall is large enough, the increase in the velocity takes place at a rate much smaller than the rate of increase of the distance. This latter property is evident either from the $1 / n$ power law or from the Kármán logarithmic velocity law. No such simplification exists for laminar flow, since the flow at a given point is affected by the whole wall. In fact, viscous uniform flow is a boundary-value problem.

These two properties of the law of velocity distribution permit its application to other cases of turbulent flow, once the constants involved in the law have been determined from tests on pipes of circular cross section. As examples of such applications there may be cited the analytical determination of the hydraulic skin friction of circular disk and flat plates $[9,10]$.

\section{(a) RESISTANCE FORMULAS FOR CIRCULAR AND INFINITELY WIDE} RECTANGULAR PIPES

As simple illustrations of the use of the hydraulic radius and of the Kármán law of velocity distribution, the coefficient of hydraulic resistance will be computed for two forms of pipes: (1) A pipe of circular cross section and (2) a rectangular pipe of infinite width. In the 
first case, the wall shear $\tau_{0}$ is the same over the entire perimeter of the section, and in the second case the variation in $\tau_{0}$ at the two sides of the pipe can be neglected, since the pipe is infinitely wide. Hence, in both cases $\tau_{0}=\bar{\tau}_{0}$, the bar denoting the average value for the section.

Defining the friction coefficient $\lambda$ in the usual way, the relation

$$
\frac{\bar{\tau}_{0}}{\rho}=\lambda \frac{\bar{u}^{2}}{8}
$$

in which $\bar{u}$ is the mean velocity of flow for the cross section, leads to the expression

where

$$
\frac{\bar{u}}{\bar{u}_{*}}=2 \sqrt{\left(\frac{2}{\lambda}\right)}
$$

$$
\bar{u}_{*}=\sqrt{ }\left(\bar{\tau}_{0} / \rho\right) \text {. }
$$

Hence as a measure of the resistance, it is sufficient to consider the ratio $\bar{u} / \bar{u}_{*}$, which will be called the "mean flow ratio," instead of the resistance coefficient $\lambda$. This practice will be followed throughout this paper.

(1) Smooth walls.-Considering now a pipe of circular cross section, both sides of the expression

$$
\frac{u}{u_{*}}=\frac{u}{\bar{u}_{*}}=a_{s}+b \ln \left(\frac{y \bar{u}_{*}}{\nu}\right), \quad\left[b=\frac{1}{\kappa}\right],
$$

which is the velocity distribution equation for a smooth surface, are multiplied by $2 \pi r d r$, and then the resulting equation is integrated between the limits $\left(r_{0}-\delta\right)$ and $0, \delta$ being the thickness of the laminar sublayer and $r_{0}$ the radius of the pipe. The flow in the laminar sublayer is negligible in comparison with the flow in the turbulent core, and hence the terms involving $\delta$ may be neglected. The resulting equation for the mean velocity of flow in a smooth-walled pipe of circular cross section is then

$$
\frac{\bar{u}}{u_{*}}=\frac{\bar{u}}{\bar{u}^{*}}=a_{s}-1.5 b+b \ln \left(\frac{r_{0} \bar{u}_{*}}{\nu}\right) .
$$

In a similar manner the equation for a smooth-walled pipe of rectangular section and of infinite width can be obtained, and is found to be

$$
\frac{\bar{u}}{u_{*}}=\frac{\bar{u}}{\bar{u}_{*}}=a_{s}-b+b \ln \left(\frac{h \bar{u}_{*}}{\nu}\right)
$$

where $h$ is half the height of the section.

Introducing the hydraulic radius, $R=r_{0} / 2$ and $R=h$, respectively, in the last two equations, they become

$$
\begin{gathered}
\frac{\bar{u}}{u_{*}}=\frac{\bar{u}}{\bar{u}_{*}}=a_{s}-0.81 b+b \ln \left(\frac{R \bar{u}_{*}}{\nu}\right), \text { and } \\
\frac{\bar{u}}{u_{*}}=\frac{\bar{u}}{\bar{u}_{*}}=a_{s}-b+b \ln \left(\frac{R \bar{u}_{*}}{\nu}\right),
\end{gathered}
$$

respectively. It should be noted that this last equation applies also to a rectangular channel of infinite width and of depth $h$. 
Now, introducing the experimentally determined values $a_{s}=5.5$. and $b=2.5$, and changing to common logarithms, the equations become

$$
\frac{\bar{u}}{u_{*}}=\frac{\bar{u}}{\bar{u}_{*}}=3.5+5.75 \log \left(\frac{R \bar{u}_{*}}{\nu}\right),
$$

for smooth-walled pipes of circular cross section, and

$$
\frac{\bar{u}}{u_{*}}=\frac{\bar{u}}{\bar{u}_{*}}=3.0+5.75 \log \left(\frac{R \bar{u}_{*}}{\nu}\right)
$$

for flow between smooth parallel walls of infinite extent. Thus, when the hydraulic radius is adopted as the characteristic length, it appears that the expressions for the average velocity become nearly identical in the two cases just considered.

(2) Rough walls.-To obtain the corresponding expressions for the mean velocity when the surfaces are rough, it is sufficient to replace $a_{s}$ in eq 31 and 32 by the value of $a_{\tau}$ given by eq 25 . Hence when the walls are rough, eq 31 and 32 become

$$
\frac{\bar{u}}{u_{*}}=\frac{\bar{u}}{\bar{u}_{*}}=a_{r o}-0.81 b+b \ln \left(\frac{R}{k}\right)
$$

for circular pipes, and

$$
\frac{\bar{u}}{u_{*}}=\frac{\bar{u}}{\bar{u}_{*}}=a_{r o}-b+b \ln \left(\frac{R}{k}\right)
$$

for parallel walls of infinite extent.

If the roughness is produced by closely packed sand grains, as in Nikuradse's experiments on rough surfaces, $a_{r 0}=8.5$, and eq 35 and 36 become

$$
\frac{\bar{u}}{u_{*}}=\frac{\bar{u}}{\bar{u}_{*}}=6.5+5.75 \log \left(\frac{R}{k_{*}}\right)
$$

for circular pipes, and

$$
\frac{\bar{u}}{u_{*}}=\frac{\bar{u}}{\bar{u}_{*}}=6.0+5.75 \log \left(\frac{R}{k_{s}}\right)
$$

for parallel walls of infinite extent.

(b) RESISTANCE FORMULAS FOR CHANNELS WITH POLYGONAL CROSS SECTIONS

In passing from a circular pipe to a polygonal channel, a complication arises from the presence of secondary currents at the corners of the channel. Prandtl [5] has explained these currents as being due to the three-dimensional character of the turbulent velocity fluctuations. In consequence, the shear at the wall corners is reduced, since otherwise the resulting dissipation would be greater than that which can be maintained by the externally furnished energy. Thus in polygonal channels the shear at the wall is not uniform. Also the free surface acts as if it were a source of friction. The turbulent fluctuations near the surface, now only two-dimensional, again are a source of energy 
dissipation, as the velocity at the surface is not uniform. If the extent of the free surface is decreased, a larger dissipation occurs, and the filaments of maximum velocity in any vertical are depressed. Accordingly, in applying Kármán's velocity law to channels, attention must be paid to these factors.

(1) Trapezoidal channels.-The expression for the mean velocity in a channel having a trapezoidal cross section will be derived next, and it will be demonstrated that the correction terms due to the variation in wall shear over the solid boundary and to the apparent shear at the free surface may be neglected without involving an error greater than a few percent. In other words, the hydraulic radius as customarily computed can be used as the characteristic length of the cross section of such a channel.

It is necessary to treat two cases; (1) when the bisectors of the internal angles intersect above the water surface, and (2) when they intersect below the water surface. (See fig. 4.)

Case 1.-Bisectors intersect above water surface. The internal angles of the cross section (see fig. 4) will be denoted by $\theta_{1}$ and $\theta_{2}$, the base width by $B_{0}$, and the depth of the water by $h$. For purposes of computation, the cross section will be divided into zones of infinitesimal width $d y$ in such a way that all portions of any given zone are at the same minimum distance $y$ from the wall.

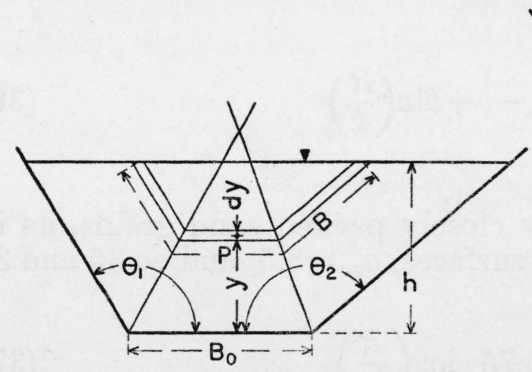

I. BISECTORS OF BASE ANGLES MEET ABOVE WATER SURFACE

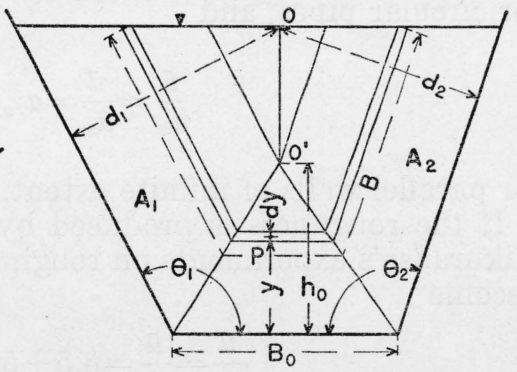

2. BISECTORS OF BASE ANGLES MEET BELOW WATER SURFACE

FIgURE 4.-Diagrams of trapezoidal channels to illustrate notation.

The velocity $u$ at a given point $P$ in one of the zones can be written as

$$
\frac{\bar{u}}{\bar{u}_{*}}=a+b \ln \left(\frac{y u_{*}}{\nu}\right)-\epsilon_{f} \frac{\bar{u}}{\bar{u}_{*}}
$$

Here $y$ is the normal distance of $P$ from the wall and $u_{*}$ is the shear velocity computed from the shear at the foot of the normal from $P$.

The term $\epsilon_{f} \bar{u} / \bar{u}_{*}$ is a correction applied to take account of the effect of the free surface.

The correction is expressed conveniently as a certain fraction $\epsilon_{f}$ of the ratio $\bar{u} / \bar{u}_{*}$, where $\bar{u}$ is the average velocity in the cross section, and $\bar{u}_{*}$ is the average shear velocity over the solid boundary. It is obvious that $\epsilon_{f}$ will be a function of the position of the point $P$. The relation of the local shear velocity $u_{*}$ at an element of the wall to the mean shear velocity can be expressed by 


$$
u_{*}=\bar{u}_{*}\left(1+\epsilon_{*}\right)
$$

Replacing $u_{*}$ in eq 39 by its value from eq 40 , and discarding some small quantities involving $\epsilon_{*}$, there results

$$
\frac{u}{\bar{u}_{*}}=a+b \ln \left(\frac{y \bar{u}_{*}}{\nu}\right)-\left(\epsilon_{f}-\epsilon_{*}\right) \frac{\bar{u}}{\bar{u}_{*}} .
$$

This may be referred to as the exact law of velocity distribution in a channel with smooth surfaces. If we neglect the flow in the laminary sublayer, the total flow through the cross section is given by

$$
\bar{u} A=\int_{\delta}^{h} u B d y,
$$

where $A$ is the area of the wetted cross section and $\delta$ is the thickness of the laminar sublayer.

The length $B$ of any zone is given by the relation

where

$$
B=p-\alpha y,
$$

$p=$ the wetted perimeter, and

$\alpha=\mathrm{a}$ function of the included angles of the form

$\alpha=\operatorname{ctn} \theta_{1}+\operatorname{ctn} \theta_{2}+2 \csc \theta_{1}+2 \csc \theta_{2}$.

Substituting in eq 42 the value of $u$ from eq 41 and the value of $B$ from eq 43 , integrating, and neglecting the small quantities involving $\delta$, there results

$$
\frac{\bar{u}}{\bar{u}_{*}}=a_{s}-b+b \ln \left(\frac{h u_{*}}{\nu}\right)+\frac{b h^{2} \alpha}{4 A}-\bar{\epsilon} \frac{\bar{u}}{\bar{u}_{*}},
$$

where $\bar{\epsilon}$ is defined as

$$
\bar{\epsilon}=\frac{1}{A} \int\left(\epsilon_{\mathcal{f}}-\epsilon_{*}\right) d A .
$$

If the $h$ in the logarithmic term is now replaced by the hydraulic radius $R$ by the substitution $h=R h / R$, and if $\beta$ is used to represent the difference

$$
\beta=\ln \left(\frac{h}{R}\right)-\frac{h^{2} \alpha}{4 A},
$$

the expression for the mean velocity of flow in a channel of trapezoidal cross section with smooth walls becomes

$$
\frac{\bar{u}}{\bar{u}_{*}}=a_{s}-b+b \ln \left(\frac{R \bar{u}_{*}}{\nu}\right)+b \beta-\bar{\epsilon} \frac{\bar{u}}{\bar{u}_{*}} .
$$

The corresponding expression for wavy walls is obtained by substituting $a_{w}$ for $a_{s}$ in eq 48 , and is

$$
\frac{\bar{u}}{\bar{u}_{*}}=a_{w}-b+b \ln \left(\frac{R \bar{u}_{*}}{\nu}\right)+b \beta-\bar{\epsilon} \frac{\bar{u}}{\bar{u}_{*}} .
$$

If the walls of the channel are rough, $a_{s}$ in eq 48 should be replaced by $a_{r}$ as given by eq 25 in which the value of $a_{r o}$ depends on the roughness of the surface under consideration. The equation for the 
mean velocity in a rough-walled channel of trapezoidal cross section then becomes

$$
\frac{\bar{u}}{\bar{u}_{*}}=a_{r o}-b+b \ln \left(\frac{R}{k}\right)+b \beta-\bar{\epsilon} \frac{u}{u_{*}} .
$$

Case 2.-Bisectors intersect below water surface. If the free surface is above the point of intersection of the bisectors of the internal angles, the value of $\beta$ must be expressed differently. (See fig. 4.) Let the bisectors of the included angles meet at a point $O^{\prime}$, at a vertical distance $h_{0}$ from the bottom. The vertical line passing through $O^{\prime}$ meets the free surface at the point $O$. The two normals drawn from $O$ to the side walls are of length $d_{1}$ and $d_{2}$. The vertical through $O$ and $O^{\prime}$ divides the area $A$ of the trapezoid into two portions $A_{1}$ and $A_{2}$. Then $\beta$ will be given by the relation

$$
\begin{gathered}
2 A \beta=\left(2 \cot \theta_{1} / 2+\tan \theta_{1}\right) h_{0}{ }^{2} \ln \left(h_{0} / d_{1}\right)+ \\
\left(2 \cot \theta_{2} / 2+\tan \theta_{2}\right) h_{0}{ }^{2} \ln \left(h_{0} / d_{2}\right)+ \\
2 A_{1} \ln \left(d_{1} / R\right)+2 A_{2} \ln \left(d_{2} / R\right)-A,
\end{gathered}
$$

where $R$ is the hydraulic radius.

The value of $\beta$ thus determined can now be substituted in eq 48 , 49 and 50 for this case.

(2) Channels of other shapes.-If the mean velocity in a channel of any other cross section is computed in the same manner, it will be found that the expressions for this velocity have the same form as those given for a trapezoidal cross section in eq 48,49 , and 50, except that the values of $\beta$ and $\bar{\epsilon}$ vary from section to section. Hence these three equations are the rational equations for the mean velocity of uniform flow in channels of constant cross section and slope, since they are derived from a rational theory.

(3) Error from neglect of the correction terms.-Eq 48, 49, and 50 also enable us to compute the magnitude of the error that is involved if we neglect certain additive terms. If these general equations are compared with the corresponding equation for a channel of infinite width (see eq 32), it will be observed that they differ from it only in containing the additive terms $b \beta-\bar{\epsilon} \quad \bar{u} / \bar{u}_{*}$. These terms may be interpreted as due to the combined effect of the existence of a free surface and of a nonuniform distribution of shear at the walls. The term $b \beta$ can be computed readily for any given shape of cross section, as this is a mere matter of geometry. Computation shows that for a triangular cross section $\beta$ is independent of the depth of the water and has the value

$$
\beta=0.19 \text {. }
$$

For a rectangular cross section it takes on the value

$$
\beta=\ln \left(1+\frac{2 h}{B_{0}}\right)-\frac{h}{B_{0}}
$$

as can be seen from eq 47 .

For a semicircular cross section, $\beta$ has the form

$$
\beta=\int_{0}^{h}\left[\ln \left(\frac{y}{R}\right)\right] \frac{B}{R} \frac{d y}{p}+1
$$

Some computed values of $\beta$ for rectangular and semicircular channels are given in table 1 . The above formulas show that $\beta$ varies with the hydraulic radius. Table 1 shows on the other hand that $\beta$ in 
itself is a small quantity. For polygonal channels other than rectangular, $\beta$ is found to be of approximately the same magnitude as for a rectangular channel. For the sake of simplicity then, we may take $\beta=0.1$ for all polygonal channels irrespective of shape, since the error thus introduced is small.

Little is known as yet about the quantity $\bar{\epsilon}$. From the manner of formation, it can be inferred that $\bar{\epsilon}$ is small, particularly in those cases where the depression of the filaments of maximum velocity is small. It is conceivable that the magnitude of $\bar{\epsilon}$ will depend on the

TABLE 1.-Values of $\beta$ for rectangular and semicircular channels

\begin{tabular}{|c|c|c|c|}
\hline \multicolumn{2}{|c|}{ Rectangular } & \multicolumn{2}{|c|}{ Semicircular } \\
\hline$R / B_{0}$ & $\beta$ & $R / r_{0}$ & $\beta$ \\
\hline $\begin{array}{r}0.05 \\
.10 \\
.15 \\
.20 \\
.25\end{array}$ & $\begin{array}{r}0.049 \\
.098 \\
.143 \\
.175 \\
.193\end{array}$ & $\begin{array}{r}0.05 \\
.15 \\
.20 \\
.30 \\
.40 \\
.50\end{array}$ & $\begin{array}{r}0.178 \\
.200 \\
.210 \\
.227 \\
.244 \\
.259\end{array}$ \\
\hline
\end{tabular}

shape of the cross section. The exact determination of its value no doubt is connected with some parameter involving the ratio of the transverse length of the free surface to the wetted perimeter.

It is very likely that $\bar{\epsilon}$ can be evaluated best by means of experiments. The above expressions, eq 48,49, and 50, indicate that in experiments for this purpose the surface characteristics of the channel wall will have to be determined in advance by tests on other forms of channels, or preferably on very wide rectangular pipes.

We leave the term $\bar{\epsilon} \bar{u} / \bar{u}_{*}$ out of consideration by assuming that it is small and can be merged with the surface characteristics $a_{s}, a_{w}$, or $a_{t 0}$. We adopt 2.5 for the value of $b$ and 0.1 for the value of $\beta$ and put

$$
\begin{aligned}
& A_{s}=a_{s}-2.5(1-\beta)=a_{s}-2.25, \\
& A_{w}=a_{w}-2.5(1-\beta)=a_{w}-2.25, \\
& A_{\tau 0}=a_{r 0}-2.5(1-\beta)=a_{r 0}-2.25 .
\end{aligned}
$$

Thus, the general equations of mean flow, eq 48, 49, and 50, now become

$$
\begin{aligned}
& \frac{\bar{u}}{\bar{u}_{*}}=A_{s}+5.75 \log \left(\frac{R \bar{u}_{*}}{\nu}\right), \\
& \frac{\bar{u}}{\bar{u}_{*}}=A_{w}+5.75 \log \left(\frac{R \bar{u}_{*}}{\nu}\right), \text { and } \\
& \frac{\bar{u}}{\bar{u}_{*}}=A_{r 0}+5.75 \log \left(\frac{R}{k}\right),
\end{aligned}
$$

for smooth, wavy, and rough surfaces, respectively. The experiments of Bazin will be examined in the light of these expressions. But prior to this examination it is permissible to effect a further simplification in the flow expression for rough channels, eq 57, by introducing the concept of "equivalent sand roughness." 


\section{(c) EQUIVALENT SAND ROUGHNESS}

The hydraulic effect of roughness elements of arbitrary shape and of arbitrary distribution can be described very conveniently by comparing it with the effect of a rough surface consisting of closely packed sand grains of the type used by Nikuradse [2] in his studies of rough pipes. Such a comparison leads to the concept of equivalent sand roughness. The size of sand grains as a measure of roughness was first suggested and used by Kármán [11]. The basis of the comparison is the similarity of velocity distribution near a rough surface. In general

$$
\frac{u}{u_{*}}=a_{r 0}+5.75 \log \left(\frac{y}{k}\right),
$$

where $k$ is a roughness height. In Nikuradse's results $a_{r 0}$ was found to have the value 8.5 , so that

$$
\frac{u}{u_{*}}=8.5+5.75 \log \left(\frac{y}{k_{s}}\right),
$$

where $k_{s}$ is the size of the closely packed sand grains. Eliminating $u / u_{*}$ between these two equations,

$$
5.75 \log k_{s}=8.5-a_{r 0}+5.75 \log k .
$$

This is the expression which gives the equivalent sand roughness $k$ s for the particular roughness $k$. Physically, if a velocity $u$ is observed at a point distant $y$ from a wall of an arbitrary roughness $k$ under a known shear, the same velocity will be obtained at the same point and for the same shear if the particular roughness is replaced by sand grains of size $k_{s}$ as given by eq 58 .

If velocity traverses do not exist for a given roughness in a channel, let us say, the determination of the equivalent sand roughness can be made to depend on the mean flow. From eq 50 after combining the $\bar{\epsilon}$ term with $a_{r 0}$, putting $b=2.5$ and $\beta=0.1$, we have

$$
a_{r 0}-5.75 \log k=\frac{\bar{u}}{\bar{u}_{*}}-5.75 \log R+2.25 .
$$

Substituting this in eq 58 , there results

$$
5.75 \log k_{s}=6.25-\left(\frac{\bar{u}}{\bar{u}_{*}}-5.75 \log R\right),
$$

from which $k_{s}$ can be computed. An advantage of this procedure is that it is not necessary to make a geometrical specification of roughness in any given case for the purpose of description. With $k_{s}$ known, the expression for the mean flow in rough channels can now be written as

$$
\frac{\bar{u}}{\bar{u}_{*}}=6.25+5.75 \log \left(\frac{R}{k_{s}}\right)
$$




\section{APPLICATION TO BAZIN'S EXPERIMENTAL DATA}

\section{DESCRIPTION OF BAZIN'S CHANNEL INSTALLATION}

The experiments of Bazin which are reviewed in this paper were made in an experimental channel located along the Bourgogne canal, near Dijon. [4] The channel was connected at the upper end with the canal which supplied the water and at the lower end with the river Ouche which received the discharge. It ran parallel with the canal for a distance of $450 \mathrm{~m}$ and then turned to the left toward the river for the remaining length of $146.5 \mathrm{~m}$. It was built of poplar planks placed longitudinally and fixed to wooden frames spaced $1.5 \mathrm{~m}$ apart. The width of the channel throughout its entire length was $2 \mathrm{~m}$. $R$ ammed clay under the bed and cement mortar applied to the exterior of the vertical walls made the channel watertight. In the initial length of $200 \mathrm{~m}$ the slope of the channel was 0.0049 ; for the next $250 \mathrm{~m}$ to the bend the slope was 0.0084 . When it was found necessary to experiment with slopes other than those given above and with different cross sections, these were invariably built of wood. To modify the slope a wooden floor was placed in the channel, and all spaces underneath were filled with clay.

The forebay at the upper end of the channel consisted of a rectangular chamber $5.40 \mathrm{~m}$ wide and $14 \mathrm{~m}$ long. The flow of water from the canal into the forebay chamber was regulated by means of four gates. Each had a width of $1 \mathrm{~m}$ and could be elevated to give a maximum opening of $0.4 \mathrm{~m}$. The final control of the flow from the forebay chamber into the experimental channel was effected by means of 12 sharp-edged square orifices made of copper. With this arrangement a very uniform discharge was easily obtained.

An assistant stationed at the gates maintained the surface of the water in the forebay at a level of $0.80 \mathrm{~m}$ above the midpoint of the orifices, guided by the indications of a float gage. During calibration the discharge of the orifices was ascertained by putting a bulkhead in the initial portion of the channel and noting the time taken to fill the basin thus created. For determining accurately the volume of the water discharged through the orifices, the discharge was made into the isolated portion of the channel after the bottom of the latter was covered with water. Thus the volume to be measured was one between two horizontal water surfaces and the vertical walls of the channel.

The profile of the water surface in each test was measured as follows. Three metal studs were placed on the upper cross piece of each channel frame, one at the midpoint and one on each side, to serve as datum points. Their heights were measured from the bottom of the bed and also from the water surface, the difference yielding the depth of water. The depth gage was a graduated rod with a sharp metal edge at its lower end. This rod was movable in a block which was rested on one of the datum studs during measurements. An examination of the tables of data shows that in a great many tests the depth was measured continually over the entire length of channel investigated. Sometimes more than 100 such depth measurements were made-never less than 40. Again, the depth that was used for computing the hydraulic radius was usually the mean of some 20,30 , or 40 such determinations. These were selected from a reach where the depth was found to be uniform. 
The profile of the channel bed was carefully determined at the commencement of each series of operations in the following simple and accurate manner. In each segment of the channel a bulkhead was placed downstream, and the section of the channel in which the slope was to be measured was filled with water. The profile of the channel bottom was then determined by depth measurements with reference to the still water surface.

The velocity traverses were made by means of a pitot-static tube of the type developed by Darcy. The constant of proportionality of the instrument was based on the results of the following two of the three methods used. In one method the surface velocities in the channel were measured both by a float and by the tube, and the results were compared. The comparison was restricted to measurements made in rectangular channels of large dimensions and great depth of flow. This comparison gave the value 1.006 for the constant. In another method the integrated discharge determined from velocity traverses by the tube was compared with the mean discharge. This method gave 0.993 . The mean of the two results, or unity, was adopted.

\section{EQUIVALENT SAND ROUGHNESS FOR SOME OF BAZIN'S CHANNELS}

The first group of data to be considered is from the experiments which Bazin made to determine the effect of roughness on the mean

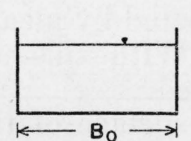

RECTANGULAR

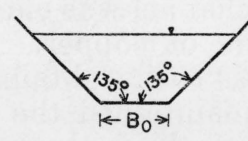

TRAPEZOIDAL I

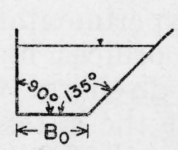

TRAPEZOIDAL II

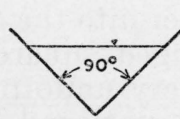

TRIANGULAR

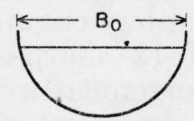

SEMICIRCULAR

SHAPES OF GHANNELS

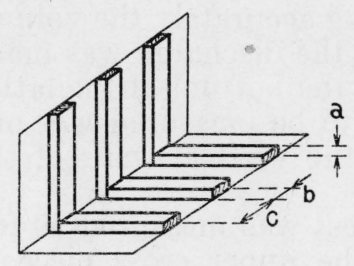

\begin{tabular}{|c|c|c|c|}
\hline \multirow{2}{*}{ STRIFS } & \multicolumn{3}{|c|}{ DIMENSIONS IN CM } \\
\cline { 2 - 4 } & $a$ & $b$ & $c$ \\
\hline CLOSELY SPACED & 1 & 2.7 & 1 \\
\hline WIDELY SPACED & 1 & 2.7 & 5 \\
\hline
\end{tabular}

\section{PLANK CHANNELS WITH WOOD STRIPS}

Figure 5.-Descriptive diagrams of Bazin's channels.

velocity of flow. The experiments were made in rectangular channels, all of practically the same width. The types of rough surfaces, which were the same for the bottom and the vertical walls in each individual case, are listed in table 2 , together with pertinent experimental data. Also see figure 5. 
TABLE 2.-Data from Bazin's tests on rough rectangular channels

\begin{tabular}{|c|c|c|c|c|c|c|c|c|}
\hline \multirow{2}{*}{ Series } & \multirow{2}{*}{ Surface } & \multirow{2}{*}{$\underset{i}{\text { Slope, }}$} & \multirow{2}{*}{$\underset{B_{0}}{\text { Width, }}$} & \multicolumn{2}{|c|}{$\begin{array}{l}\text { Hydraulic } \\
\text { radius, } R\end{array}$} & \multicolumn{2}{|c|}{$\begin{array}{c}\text { Mean velocity, } \\
\bar{u}\end{array}$} & \multirow{2}{*}{$\begin{array}{c}\text { Tem- } \\
\text { pera- } \\
\text { ture, } \theta\end{array}$} \\
\hline & & & & $\begin{array}{l}\text { Mini- } \\
\text { mum }\end{array}$ & $\begin{array}{l}\text { Maxi- } \\
\text { mum }\end{array}$ & $\begin{array}{l}\text { Mini- } \\
\text { mum }\end{array}$ & $\begin{array}{l}\text { Maxi- } \\
\text { mum }\end{array}$ & \\
\hline & $\begin{array}{l}\text { Cement_. } \\
\text { Brick _... } \\
\text { Fine gravel 1 } \\
\text { Coarse gravel } \\
\text { Planks............ }\end{array}$ & $\begin{array}{l}0.0049 \\
.0049 \\
.0049 \\
.0049 \\
.00824\end{array}$ & $\begin{array}{c}c m \\
181.2 \\
191.1 \\
183.2 \\
186.1 \\
199.0\end{array}$ & $\begin{array}{l}c m \\
5.11 \\
5.86 \\
7.61 \\
8.88 \\
4.47\end{array}$ & $\begin{array}{l}c m \\
21.23 \\
23.74 \\
27.72 \\
30.09 \\
19.19\end{array}$ & $\begin{array}{r}c \mathrm{~cm} / \mathrm{sec} \\
101.8 \\
83.9 \\
65.8 \\
54.7 \\
107.4\end{array}$ & \begin{tabular}{|r|}
$\mathrm{cm} / \mathrm{sec}$ \\
246.0 \\
204.7 \\
169.7 \\
149.3 \\
261.2
\end{tabular} & $\begin{array}{l}{ }^{\circ} C . \\
12.0 \\
19.0 \\
14.5 \\
16.0 \\
8.5\end{array}$ \\
\hline & $\left\{\begin{array}{l}\text { Planks with } \\
\text { wood strips. }\end{array}\right.$ & $\left\{\begin{array}{l}0015 \\
0059 \\
00886\end{array}\right.$ & $\begin{array}{l}196.6 \\
196.1 \\
195.2\end{array}$ & $\begin{array}{l}9.21 \\
6.26 \\
5.56\end{array}$ & $\begin{array}{l}32.81 \\
24.09 \\
22.14\end{array}$ & $\begin{array}{l}50.2 \\
76.2 \\
86.8\end{array}$ & $\begin{array}{l}127.8 \\
197.4 \\
221.2\end{array}$ & $\begin{array}{r}8.5 \\
7.0 \\
14.0\end{array}$ \\
\hline & $\left\{\begin{array}{l}\text { Planks with widely spaced } \\
\text { wood strips. }{ }^{3}\end{array}\right.$ & $\left\{\begin{array}{l}.0015 \\
0059 \\
00886\end{array}\right.$ & $\begin{array}{l}196.0 \\
196.0 \\
195.1\end{array}$ & $\begin{array}{r}11.53 \\
8.05 \\
7.06\end{array}$ & $\begin{array}{l}39.60 \\
29.42 \\
26.99\end{array}$ & $\begin{array}{l}39.0 \\
58.1 \\
67.3\end{array}$ & $\begin{array}{r}94.9 \\
149.8 \\
169.8\end{array}$ & $\begin{array}{r}16.5 \\
7.5 \\
16.5\end{array}$ \\
\hline
\end{tabular}

1 Gravel from 1 to $2 \mathrm{~cm}$ in diameter.

2 Gravel from 3 to $4 \mathrm{~cm}$ in diameter.

3 See figure 5 .

To ascertain whether the mean velocity of flow in a channel of a given roughness $k$ is affected by the kinematic viscosity, it is sufficient to investigate the relation between the quantities $\left(\bar{u} / \bar{u}_{*}-5.75 \log R\right)$ and $\log \left(\bar{u}_{*} / \nu\right)$.

In order to compute the principal quantities involved in the comparison, the following test data were taken from Bazin: The temperature of the water, $\theta$; the hydraulic radius, $R$, in centimeters; the mean velocity of flow, $\bar{u}$, in centimeters per second; and the quantity $A=$ $R i / \bar{u}^{2}$, which is a measure of the hydraulic resistance. As $A$ is not a dimensionless quantity, it was multiplied by $g$, the acceleration of gravity, to make it dimensionless.

In a channel the mean shear velocity is given by

thus

$$
\bar{u}_{*}=\sqrt{(\text { Rig })}
$$

$$
\bar{u} / \bar{u}_{*}=1 / \sqrt{(g A)} \text {, and } \bar{u}_{*}=\bar{u} \sqrt{(g A)} .
$$

The kinematic viscosity $\nu$ follows from the temperature $\theta$.

The results of the computations are shown in figure 6 , where $\left(\bar{u} / \bar{u}_{*}-5.75 \log R\right)$ is plotted as a function of $\log \left(\bar{u}_{*} / \nu\right)$.

It is seen that in these tests the observed points for each channel can be represented by a straight line parallel to the axis of $\log \left(\bar{u}_{*} / \nu\right)$. Hence, the quantity $\left(\bar{u} / \bar{u}_{*}-5.75 \log R\right)$ is a constant. Therefore, the quantity $\left(\bar{u} / \bar{u}_{*}-5.75 \log R / k\right)$ is also a constant and thus is independent of $k \bar{u}_{*} / \nu$, where $k$ would be the actual roughness heights of any of the roughnesses employed. Thus in these tests the channels, including the channel with the cement walls, were hydrodynamically rough.

At this point attention may be invited particularly to the two groups of tests which were made with the channels having wooden strips using three different slopes. It is seen that, in this specific manner of presenting and analyzing the experimental material, the data taken with the different slopes are hardly differentiable from each other. Lindquist [11] in considering the same data compared the mean flow in these channels on the basis of Reynolds number, $R \bar{u} / \nu$. But this 
method of treatment did not yield a simple correlation of the results. The underlying difficulty now can be readily understood, since the appropriate criterion of the hydraulic roughness is obtained by using $k \bar{u}_{*} / \nu$ and not $R \bar{u} / \nu$. The Blasius method of plotting the hydraulic friction factor $\lambda$ against $R \bar{u} / \nu$ is satisfactory for rough pipes, as the relative roughness $k / R$ remains the same for variable $\bar{u}$. In channels, on the other hand, a variable $\bar{u}$ signifies a variable $k / R$.

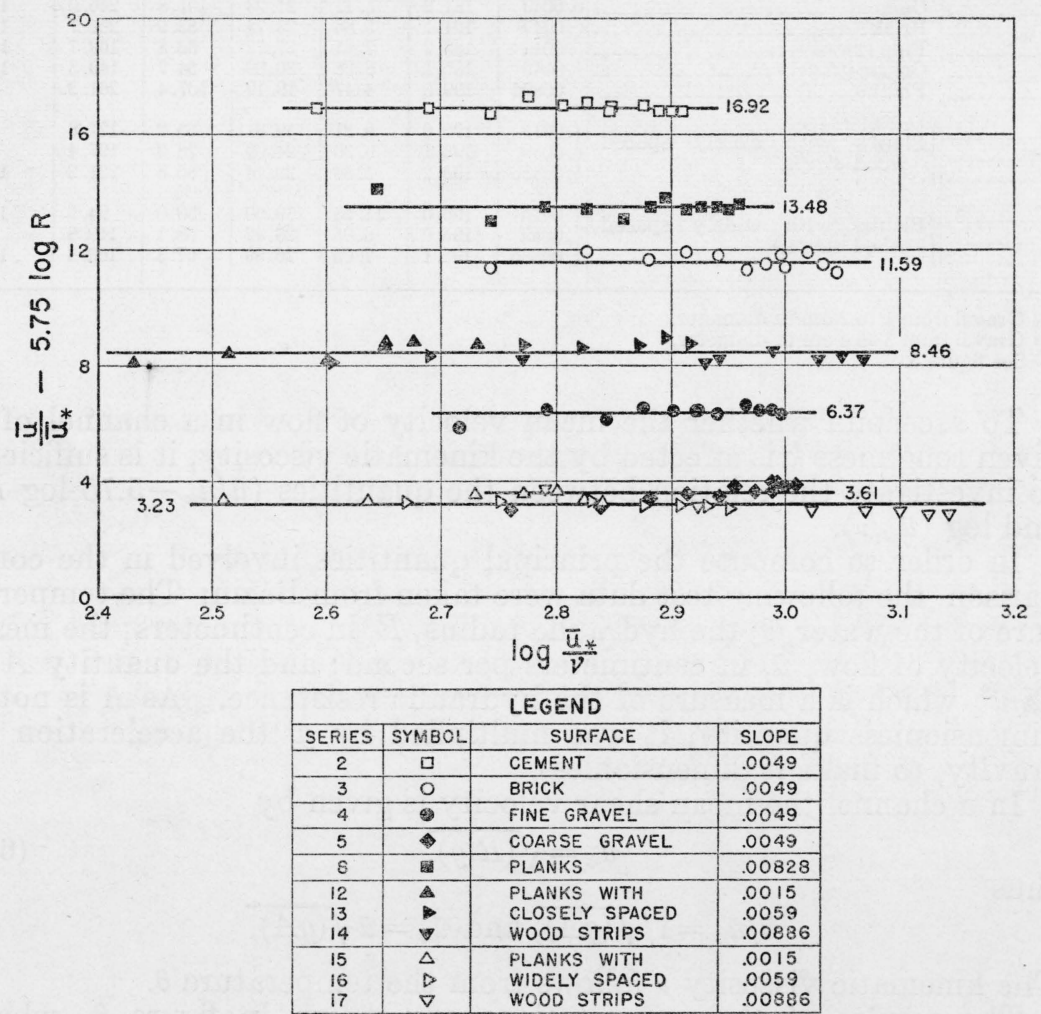

FiguRE 6.-Quantity $\left(\bar{u} / \bar{u}_{*}-5.75 \log R\right)$ as a function of $\log \left(\bar{u}_{*} / \nu_{*}\right)$ for rough rectangular channels.

Basic data from Bazin.

The results shown in figure 6 indicate that the rational formulas for the mean flow which were assumed in the beginning are actually serviceable. To complete the examination it now remains to evaluate the equivalent sand roughness for each channel, using eq 59. The different quantities which are necessary for the computations are given in table 3 . The values of the quantities $R / B_{0}$ and $Y$ in table 3 are the averages from all the observations for a given channel. The resulting equivalent sand roughness is given in the next to the last column. 
TABLE 3.-Computation of equivalent sand roughness $k_{s}$ for rough rectangular channels listed in table 2

$\left(5.75 \log k_{3}=6.25-\left(\vec{u} / \bar{u}_{*}-5.75 \log R\right)=6.25-Y_{*}\right)$

\begin{tabular}{|c|c|c|c|c|c|c|c|}
\hline Series & Suriace & $R / B_{0}$ & $Y$ & $6.35-\bar{x}$ & $\log k_{s}$ & $k_{s}$ & $R / k$, \\
\hline $\begin{array}{l}2 \\
3 \\
4 \\
8\end{array}$ & $\begin{array}{l}\text { Cement } \\
\text { Brick } \\
\text { Fine gravel } 1 \\
\text { Coarse gravel }{ }^{2} \\
\text { Planks. }\end{array}$ & $\begin{array}{l}0.080 \\
.084 \\
.106 \\
.116 \\
.067\end{array}$ & $\begin{array}{r}16.92 \\
11.59 \\
6.37 \\
3.61 \\
13.58\end{array}$ & $\begin{array}{r}-10.67 \\
-5.34 \\
-0.12 \\
+2.64 \\
-7.33\end{array}$ & $\begin{array}{r}-1.856 \\
-0.928 \\
-.021 \\
+.459 \\
-1.275\end{array}$ & $\begin{array}{c}c m \\
0.014 \\
.118 \\
.952 \\
2.88 \\
0.053\end{array}$ & $\begin{array}{c}1,030 \\
135 \\
20 \\
7.4 \\
253\end{array}$ \\
\hline 12 & $\left\{\begin{array}{l}\text { Planks with closely spaced wood } \\
\text { strips }{ }^{3} \text {. }\end{array}\right.$ & .090 & 8.46 & -2.21 & -0.384 & .413 & 43 \\
\hline $15-16$ & $\begin{array}{l}\text { Planks with widely spaced wood } \\
\text { strips. }^{3}\end{array}$ & .110 & 3.23 & +3.02 & +.526 & 3. 36 & 6. 3 \\
\hline
\end{tabular}

1 Gravel from 1 to $2 \mathrm{~cm}$ in diameter.

2 Gravel from 3 to $4 \mathrm{~cm}$ in diameter.

3 See figure 5 .

In this connection it is interesting to note that the equivalent sand roughness of the fine gravel, 1 to $2 \mathrm{~cm}$ in diameter, is 0.95 , and that of the coarse gravel, 3 to $4 \mathrm{~cm}$ in diameter, is 2.9 (table 3 ). The difference between the equivalent sand roughness and the nominal size of the gravel is not very large. Bazin does not give the proportions of different sizes in his gravels. It is quite possible that the mean size of the gravel was close to 1 and $3 \mathrm{~cm}$, respectively, in which case the agreement between the equivalent sand roughness and the actual gravel size is good. If this was not the case, the difference may be the result of the way in which the individual particles of gravel were distributed, or of the depth to which they were embedded in the supporting cement.

The analysis of Bazin's experiments on the effect of the roughness of channels, therefore, leads to the formula

$$
\frac{\bar{u}}{\bar{u}_{*}}=6.25+5.75 \log \left(\frac{R}{k_{s}}\right) \text {, }
$$

where $k_{s}$, the equivalent sand roughness, has the numerical values given in table 3 .

Adopting this form of expression for the mean flow, Manning's formula, which is used extensively in engineering work, may be changed so as to contain the equivalent sand roughness in the place of the coefficient $n$. The advantage of such a change will be discussed later.

\section{SURFACES OF WOOD AS EXAMPLES OF WAVINESS}

In some of Bazin's experiments the effect of kinematic viscosity on the mean velocity of flow can be seen. From the experiments belonging to this category (see table 4), let series 28 and 29 be considered first. These tests were made in small rectangular channels $10 \mathrm{~cm}$ wide. The channels were prepared from four pieces of firwood, about $5 \mathrm{~m}$ long, hollowed out to a cross section of $10 \mathrm{by} 10 \mathrm{~cm}$. They were assembled end to end, and in the entire length there were only three joints. The surfaces were made as smooth as possible. The slopes used were 0.0047 and 0.0152 . The data obtained from the 
tests are shown in figure 7 , in which $\bar{u} / \bar{u}_{*}$ is plotted against log $\left(R \bar{u}_{*} / \nu\right)$. It appears that the experimental points can be represented with sufficient accuracy by a straight line. This line has the same inclination as the two straight lines in the upper part of the figure, which represent the variation of the mean velocity of flow with kinematic viscosity in smooth circular pipes and in smooth rectangular pipes of very great width. The interpretation of this fact is that the polished

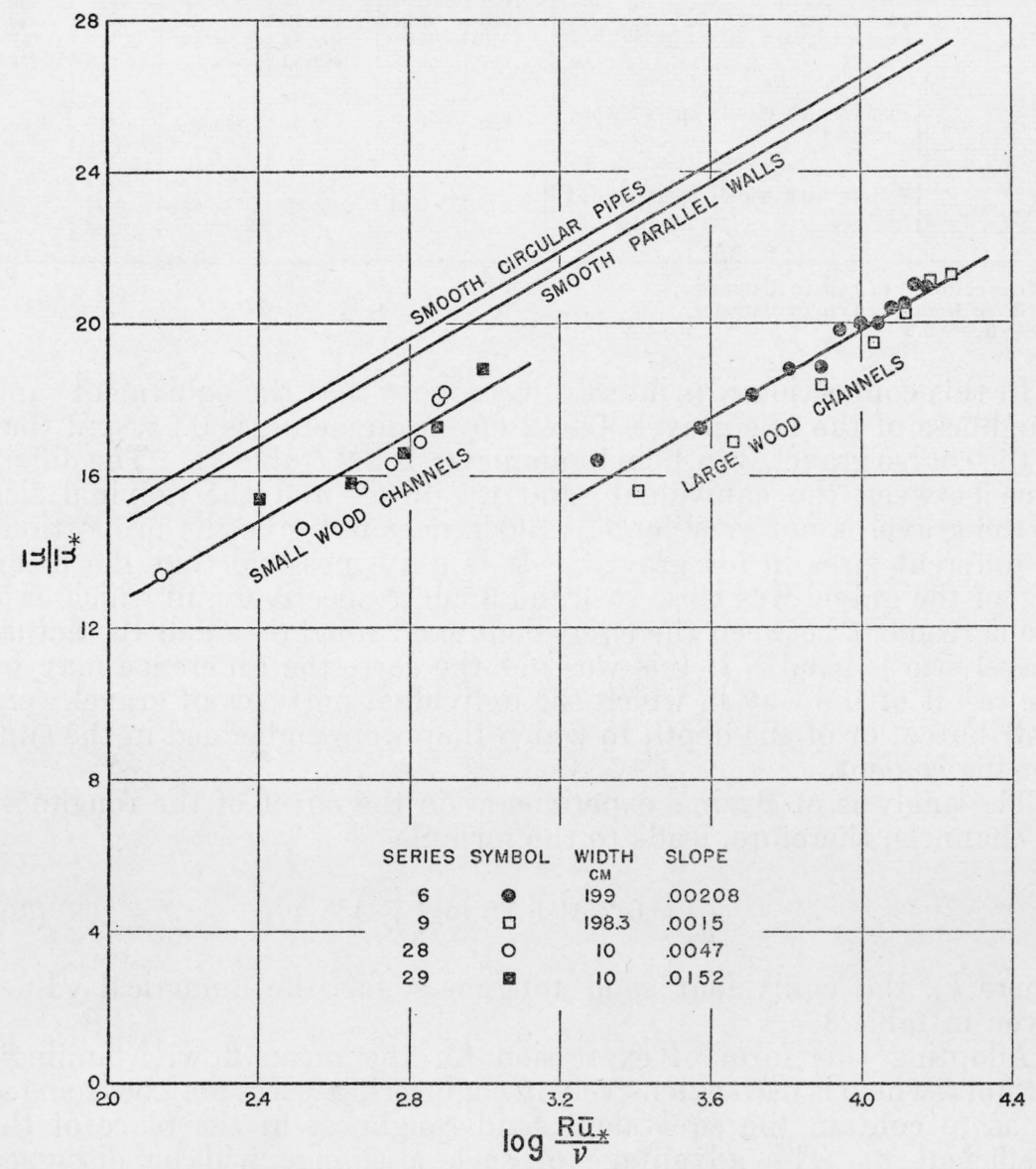

FigURe 7.-Mean flow ratio $\bar{u} / \bar{u}_{*}$ as a function of $\log \left(R \bar{u}_{*} / \nu\right)$ for small and large rectangular wood channels, illustrating characteristics of channels with wavy surfaces as compared with smooth pipes.

\section{Basic data from Bazin}

surface of firwood can not be considered as hydrodynamically smooth, since the indicated flow is less than that for a smooth surface. However, it is of a type classified customarily as wavy, since the effect of viscosity is similar to that obtained with a smooth surface. The formula for the flow as indicated by the line passing through the experimental points is 


$$
\frac{\bar{u}}{\bar{u}_{*}}=1.3+5.75 \log \left(\frac{R \bar{u}_{*}}{\nu}\right),
$$

which is of the same form as eq 56 with $a_{w}=1.3$.

TABLE 4.--Rectangular wood channels with wavy surfaces

[Data from Bazin]

\begin{tabular}{|c|c|c|c|c|c|c|c|c|}
\hline \multirow{2}{*}{ Series } & \multirow{2}{*}{ Surface } & \multirow{2}{*}{ Slope, $i$} & \multirow{2}{*}{$\begin{array}{c}\text { Width, } \\
B_{0}\end{array}$} & \multicolumn{2}{|c|}{ Hydraulic radius, $R$} & \multicolumn{2}{|c|}{ Mean velocity, $\bar{u}$} & \multirow{2}{*}{$\begin{array}{c}\text { Tem- } \\
\text { pera- } \\
\text { ture, } \theta\end{array}$} \\
\hline & & & & Minimum & Maximum & Minimum & Maximum & \\
\hline $\begin{array}{l}28 \\
29\end{array}$ & $\begin{array}{l}\text { Polished fir... } \\
\text { D.... }\end{array}$ & $\begin{array}{r}0.0047 \\
.0152\end{array}$ & $\begin{array}{l}c m \\
10.0 \\
10.0\end{array}$ & $\begin{array}{r}c m \\
0.80 \\
.92\end{array}$ & $\begin{array}{r}\boldsymbol{c} m \\
2.84 \\
2.25\end{array}$ & $\begin{array}{r}\mathrm{cm} / \mathrm{sec} \\
27.3 \\
57.1\end{array}$ & $\begin{array}{r}\mathrm{cm} / \mathrm{sec} \\
65.8 \\
108.6\end{array}$ & $\begin{array}{l}{ }^{\circ} C \\
10.0 \\
10.0\end{array}$ \\
\hline $\begin{array}{l}6 \\
9\end{array}$ & Poplar planks & $\begin{array}{l}.00208 \\
.0015\end{array}$ & $\begin{array}{l}199.0 \\
198.3\end{array}$ & $\begin{array}{l}\text { 7. } 35 \\
8.42\end{array}$ & $\begin{array}{l}28.09 \\
30.42\end{array}$ & $\begin{array}{l}63.5 \\
54.8\end{array}$ & $\begin{array}{l}158.7 \\
142.0\end{array}$ & $\begin{array}{l}7.0 \\
14.05\end{array}$ \\
\hline
\end{tabular}

A similar effect of the kinematic viscosity is also noticeable in the results of the tests made in the larger channels of wooden planks at the smaller slopes. The data, which were obtained from the experiments of series 6 and 9 (table 4), that is, from the series of the smaller slopes, are reproduced in figure 7. Again in this case the distribution of the experimental points can be represented by a straight line with the same inclination as that of the lines corresponding to smooth circular pipes and smooth rectangular pipes of great width. In these tests with large wooden channels, then, the effect of kinematic viscosity is important when the slopes are small. Thus for the smaller slopes the surfaces are to be reckoned as hydrodynamically wavy.

Yet in the previous section a similar surface is interpreted as being hydrodynamically rough. The reason for this double designation of the same surface perhaps can be clarified if all the data for large rectangular wooden channels given in table 5 are considered as a whole. For this purpose it is preferable to study the relation between $\left(\bar{u} / \bar{u}_{*}-5.75 \log R\right)$ and $\log \left(\bar{u}_{*} / \nu\right)$ as plotted in figure 8 . Two straight lines are selected to represent the distribution of the experimental points, one horizontal and the other inclined. The horizontal line is taken from figure 6 and applies to the tests of series 8; the inclined line is taken from figure 7 and applies to the tests of series 6 and 9 . The observed points, therefore, can be divided into two groups. In one group, all the points fall near the inclined line, which means that the associated flows vary with viscosity. In the other group all the points fall near the horizontal line, which means that the associated flows do not depend on viscosity. The lines intersect at a point given by $\log \left(\bar{u}_{*} / v\right)=2.9$. To derive a critical number representing this intersection, use may be made of the equivalent sand roughness already obtained for such wooden surfaces. See table 3 . With $k_{s}=0.053 \mathrm{~cm}$, or $\log k_{s}=-1.275$, the criterion that is sought for is $\log$ $\left(k_{s} \bar{u}_{*} / \nu\right)=1.625$ or $k_{s} \bar{u}_{*} / \nu=42.2$. Accordingly the unplaned wooden surfaces of the larger channels behave as wavy surfaces, when $k_{s} \bar{u}_{*} / \nu 乏 42.2$.

The mean velocity of flow for these channels with wavy surfaces, as derived from figure 7 , is 8.

$$
\frac{\bar{u}}{\bar{u}_{*}}=-3.0+5.75 \log \left(\frac{R \bar{u}_{*}}{\nu}\right) .
$$


TABLE 5.-Data from Bazin's tests on large rectangular wood channels

\begin{tabular}{|c|c|c|c|c|c|c|c|}
\hline \multirow{2}{*}{ Series } & \multirow{2}{*}{ Slope, $i$} & \multirow{2}{*}{$\begin{array}{c}\text { Width, } \\
B_{0}\end{array}$} & \multicolumn{2}{|c|}{ Hydraulic radius, $R$} & \multicolumn{2}{|c|}{ Mean velocity, $\tilde{u}$} & \multirow{2}{*}{$\begin{array}{l}\text { Temper- } \\
\text { ature, } \theta\end{array}$} \\
\hline & & & Minimum & Maximum & Minimum & Maximum & \\
\hline & $\begin{array}{c}0.00208 \\
.0049 \\
.00824\end{array}$ & $\begin{array}{l}c m \\
199.0 \\
199.0 \\
199.0\end{array}$ & $\begin{array}{l}c m \\
7.35 \\
5.73 \\
4.47\end{array}$ & $\begin{array}{l}c m \\
28.09 \\
22.15 \\
19.19\end{array}$ & $\begin{array}{r}\mathrm{cm} / \mathrm{sec} . \\
63.5 \\
82.6 \\
107.4\end{array}$ & $\begin{array}{r}\mathrm{cm} / \mathrm{sec} . \\
158.7 \\
217.9 \\
261.2\end{array}$ & $\begin{array}{r}{ }^{\circ} C \\
7.0 \\
8.5 \\
8.5\end{array}$ \\
\hline $\begin{array}{l}9 \\
10 \\
11\end{array}$ & $\begin{array}{l}.0015 \\
.0059 \\
.00839\end{array}$ & $\begin{array}{l}198.3 \\
198.7 \\
198.2\end{array}$ & $\begin{array}{l}8.42 \\
5.24 \\
4.46\end{array}$ & $\begin{array}{l}30.42 \\
20.91 \\
18.94\end{array}$ & $\begin{array}{r}54.8 \\
91.0 \\
108.0\end{array}$ & $\begin{array}{l}142.0 \\
234.9 \\
266.4\end{array}$ & $\begin{array}{l}14.05 \\
14.5 \\
16.0\end{array}$ \\
\hline
\end{tabular}

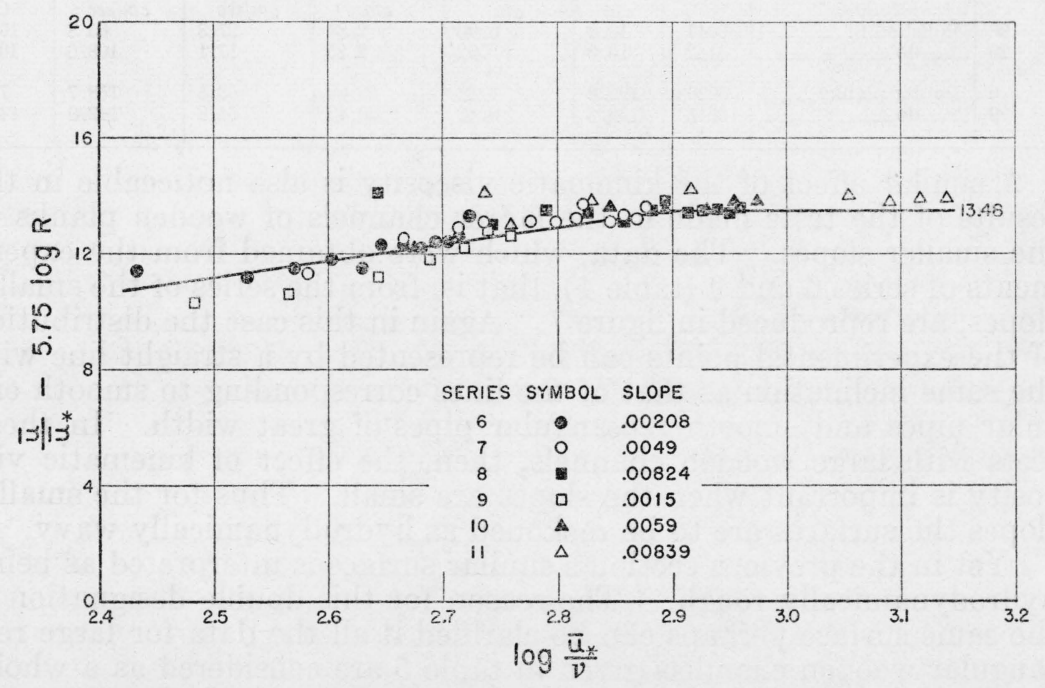

FiguRe 8.-Quantity $\left(\bar{u} / \bar{u}_{*}-5.75 \log R\right)$ as a function of $\log \left(\bar{u}_{*} / \nu\right)$ for large rectangular wood channels, illustrating transition from waviness io roughness.

Basic data from Bazin

It is interesting to note that the value of the critical number given above for the transition of the surface characteristic from waviness to roughness is somewhat less than the upper criterion which Nikuradse found for his sand-covered surfaces, which was $k_{s} \bar{u}_{*} / \nu=67$.

\section{EFFECT OF SHAPE OF CROSS SECTION ON MEAN VELOCITY}

Bazin was also interested in the possible effect of the shape of channels on the mean velocity of flow. The experiments to this end were carried out in channels with wooden walls. In what follows only those experiments in which the wooden surfaces have shown themselves to be hydrodynamically rough will be considered. These are listed in table 6 . Also see figure 5. 
TABLE 6.-Data from Bazin's tests on wood channels of various shapes ${ }^{1}$

\begin{tabular}{|c|c|c|c|c|c|c|c|c|}
\hline \multirow{2}{*}{ Series } & \multirow{2}{*}{ Shape 1} & \multirow{2}{*}{ Slope, $i$} & \multirow{2}{*}{$\begin{array}{l}\text { Width, } \\
B_{0}\end{array}$} & \multicolumn{2}{|c|}{$\begin{array}{l}\text { Hydraulic ra- } \\
\text { dius, } R\end{array}$} & \multicolumn{2}{|c|}{ Mean velocity, } & \multirow{2}{*}{$\begin{array}{l}\text { Tempera- } \\
\text { ture. } \theta\end{array}$} \\
\hline & & & & $\begin{array}{l}\text { Mini- } \\
\text { mum }\end{array}$ & $\begin{array}{l}\text { Maxi- } \\
\text { mum }\end{array}$ & $\begin{array}{l}\text { Mini- } \\
\text { mum }\end{array}$ & $\begin{array}{l}\text { Maxi- } \\
\text { mum }\end{array}$ & \\
\hline & \begin{tabular}{c} 
Rectangular \\
\hdashline do \\
\hdashline do
\end{tabular} & $\begin{array}{c}0.00824 \\
.00839 \\
.0049\end{array}$ & $\begin{array}{l}c m \\
199.0 \\
199.2 \\
119.7\end{array}$ & $\begin{array}{l}c m \\
4.47 \\
4.46 \\
7.17\end{array}$ & $\begin{array}{c}c m \\
19.19 \\
18.94 \\
25.57\end{array}$ & $\begin{aligned} c m / s e c \\
107.4 \\
108.0 \\
102.6\end{aligned}$ & $\begin{array}{l}c m / s e c \\
261.4 \\
266.4 \\
231.3\end{array}$ & $\begin{array}{c}{ }^{\circ} \mathrm{C} \\
8.5 \\
16.0 \text { to } 21.0 \\
8.0\end{array}$ \\
\hline $\begin{array}{l}21 \ldots \\
22- \\
23\end{array}$ & $\begin{array}{l}\text { Trapezoidal I- } \\
\text { Trapezoidal II. } \\
\text { Triangular. }\end{array}$ & $\begin{array}{l}.0015 \\
.0049 \\
.0049\end{array}$ & $\begin{array}{r}100.0 \\
94.5\end{array}$ & $\begin{array}{r}10.18 \\
7.85 \\
9.97\end{array}$ & $\begin{array}{l}33.43 \\
25.51 \\
25.57\end{array}$ & $\begin{array}{r}73.0 \\
109.0 \\
125.8\end{array}$ & $\begin{array}{l}148.5 \\
241.6 \\
236.3\end{array}$ & $\begin{array}{r}7.0 \\
24.5 \\
22.0\end{array}$ \\
\hline & Semicircular.- & .0015 & 140.0 & 11.89 & 35.11 & 79.5 & 168.9 & 22.5 \\
\hline
\end{tabular}

1 See figure 5.

From the test data of these series the quantity $\left(\bar{u} / \bar{u}_{*}-5.75 \log R\right)$ was computed for corresponding values of $\log \left(\bar{u}_{*} / \nu\right)$. The results are plotted in figure 9 . It is seen that $\left(\bar{u} / \bar{u}_{*}-5.75 \log R\right)$ is practically independent of $\log \left(\bar{u}_{*} / \nu\right)$, except possibly for the semicircular section. The variation of $\left(\bar{u} / \bar{u}_{*}-5.75 \log R\right)$ with $\log \left(\bar{u}_{*} / \nu\right)$ in the results for the semicircular section need not be interpreted as being necessarily due to the effects of kinematic viscosity. For, in the first place, if the correction term $2.5 \beta$ is introduced using the values in table 1 , the variation appears to be less pronounced; and in the

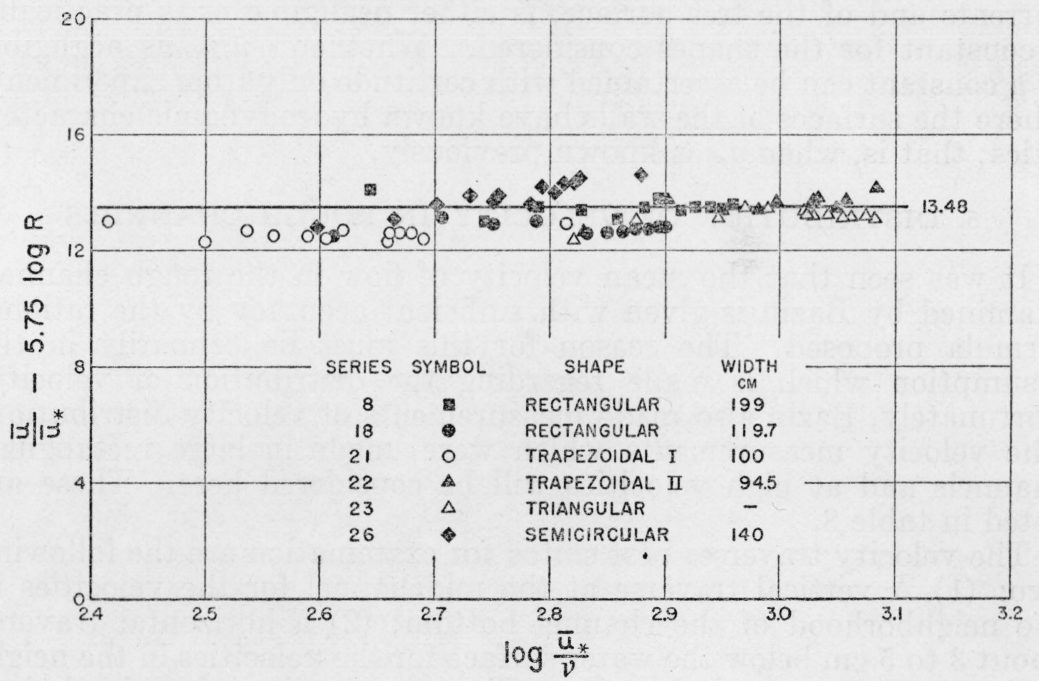

FigURE 9.-Quantity $\left(\bar{u} / \bar{u}_{*}-5.75 \log R\right)$ as a function $\log \left(\bar{u}_{*} / \nu\right)$ for rough wooden channels of various shapes.

Basic data from Bazin.

second place, the corrective term $\bar{\epsilon} \bar{u} / \bar{u}_{*}$ which was discarded in this discussion, is perhaps important in the case of the semicircular channel.

Table 7 has been prepared to show the effect of the shape of a channel on the mean velocity in these tests. The values given are the averages from the experiments of each series. In considering 
these average values it is seen that the quantity $\left(\bar{u} / \bar{u}_{*}-5.75 \log R\right)$ varies but little in the channels of different shapes. If it is permissible to assume that the wooden material in every channel had the same equivalent sand roughness $k_{s}$, then the conclusion to be drawn is that the mean velocity of flow is practically independent of the shape of the channel; that is, in two channels of different shapes but of the same slope, the mean velocity of flow will be the same if the hydraulic radii are equal.

TaBle 7.-Mean velocity of flow in wood channels of various shapes

[Values of $Y=\left(\bar{u} / \bar{u}_{*}-5.75 \log R\right)$ for the channels listed in table 6.]

\begin{tabular}{|c|c|c|}
\hline Series & Shape & Y \\
\hline $\begin{array}{l}8 \ldots \ldots \\
11 \ldots \ldots \\
18 \\
18 . . .\end{array}$ & $\begin{array}{l}\text { Rectangular } \\
\text { do do } \\
\end{array}$ & $\begin{array}{l}13.48 \\
13.95 \\
12.80\end{array}$ \\
\hline $221 \ldots$ & $\begin{array}{l}\text { Trapezoidal I } \\
\text { Trapezoidal II } \\
\text { Triangular }\end{array}$ & $\begin{array}{l}12.56 \\
13.57 \\
13.15\end{array}$ \\
\hline $26 \ldots$ & Semicircular.... & 13.86 \\
\hline Average & 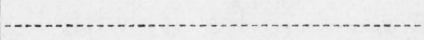 & 13.34 \\
\hline
\end{tabular}

This conclusion will be in agreement with the theoretical formulation of the rational formulas for the mean velocity, provided that in these formulas the term $\bar{\epsilon} \bar{u} / \bar{u}_{*}$, expressing the effect of the secondary currents and of the free surface, is either negligible or is practically a constant for the shapes considered. Whether $\bar{\epsilon} \bar{u} / \bar{u}_{*}$ is negligible or a constant can be ascertained with certitude only from experiments where the surfaces of the walls have known hydrodynamic characteristics; that is, when $a_{r 0}$ is known previously.

\section{DISTRIBUTION OF VELOCITY IN ROUGH CHANNELS}

It was seen that the mean velocity of flow in the rough channels examined by Bazin is given with sufficient accuracy by the rational formula proposed. The reason for this must lie primarily in the assumption which is made regarding the distribution of velocity. Fortunately, Bazin also made measurements of velocity distribution. The velocity measurements which were made in large rectangular channels and at high velocities will be considered here. These are listed in table 8.

The velocity traverses best suited for examination are the following two: (1) A vertical traverse at the midchannel for the velocities in the neighborhood of the channel bottom; (2) a horizontal traverse about 3 to $5 \mathrm{~cm}$ below the water surface for the velocities in the neighborhood of the vertical walls. The examination that is desired consists in seeing how accurately the relation

$$
\frac{u}{u_{*}}=8.5+5.75 \log \left(\frac{y}{k_{s}}\right)
$$

which is the assumed relation for rough surfaces, is confirmed. Here $u$ is the velocity at a distance $y$ from the nearest point on the wall at which $u_{*}$ is the shear velocity. 
TABLE 8.-Distribution of shear at the bottom of rough rectangular channels.

$S=$ distance from nearest corner.

$h=$ depth of water.

$B_{0}=$ width of channel.

\begin{tabular}{|c|c|c|c|c|c|}
\hline \multicolumn{2}{|c|}{$\begin{array}{l}\text { Series 55, cement. } \\
\qquad \begin{array}{c}h / B_{0}=0.15 \\
\bar{u} / \bar{u}_{\star}=24.4\end{array}\end{array}$} & \multicolumn{2}{|c|}{$\begin{array}{c}\text { Series } 56, \text { fine } \\
\text { gravel. } \\
h / B_{0}=0.28 \\
\bar{u} / \bar{u}_{*}=14.7\end{array}$} & \multicolumn{2}{|c|}{$\begin{array}{c}\text { Series 57, coarse } \\
\text { gravel. } \\
h / B_{0}=0.21 \\
\bar{u} / \bar{u}_{*}=11.5\end{array}$} \\
\hline $2 S / B_{0}$ & $\bar{u}_{*} / \bar{u}_{*}$ & $2 S / B_{0}$ & $u_{*} / \bar{u}_{*}$ & $2 S / B_{0}$ & $u_{*} / \bar{u}_{*}$ \\
\hline $\begin{array}{l}1.00 \\
0.67 \\
.34 \\
.095 \\
.044\end{array}$ & $\begin{array}{r}1.07 \\
1.07 \\
0.98 \\
.87 \\
.89\end{array}$ & $\begin{array}{r}1.00 \\
0.67 \\
.35 \\
.13 \\
.10 \\
.05\end{array}$ & $\begin{array}{r}1.16 \\
1.10 \\
0.94 \\
.88 \\
.82 \\
.78\end{array}$ & $\begin{array}{l}1.00 \\
0.69 \\
.37 \\
.14 \\
.10 \\
.06\end{array}$ & $\begin{array}{r}1.20 \\
1.11 \\
0.93 \\
.82 \\
.76 \\
.72\end{array}$ \\
\hline \multicolumn{2}{|c|}{$\begin{array}{c}\text { Series } 59, \text { plank. } \\
h / B_{0}=0.13 \\
\bar{u} / \bar{u}_{*}=21.4\end{array}$} & \multicolumn{2}{|c|}{$\begin{array}{c}\text { Series } 61, \text { plank. }{ }^{a} \\
H / B_{0}=0.25 \\
\bar{u} / \bar{u}_{*}=17.4\end{array}$} & \multicolumn{2}{|c|}{$\begin{array}{c}\text { Series } 65, \text { plank } .^{b} \\
h / B_{0}=0.21 \\
\bar{u} / \bar{u}_{*}=11.5\end{array}$} \\
\hline $2 S / B_{0}$ & $u_{*} / \bar{u}_{*}$ & $2 S / B_{0}$ & $u_{*} / \bar{u}_{*}$ & $2 S / B_{0}$ & $u_{*} / \vec{u}_{*}$ \\
\hline $\begin{array}{r}1.00 \\
0.80 \\
.60 \\
.40 \\
.20 \\
.10 \\
.03\end{array}$ & $\begin{array}{l}1.00 \\
1.07 \\
1.06 \\
1.04 \\
0.92 \\
.88 \\
.78\end{array}$ & $\begin{array}{r}1.00 \\
0.80 \\
.39 \\
.19 \\
.09 \\
.04\end{array}$ & $\begin{array}{r}1.14 \\
1.12 \\
0.98 \\
.92 \\
.85 \\
.79\end{array}$ & $\begin{array}{r}1.00 \\
0.80 \\
.60 \\
.40 \\
.20 \\
.10 \\
.04\end{array}$ & $\begin{array}{r}1.15 \\
1.12 \\
1.08 \\
0.96 \\
.86 \\
.78 \\
.63\end{array}$ \\
\hline
\end{tabular}

a Widely spaced strips.

$\checkmark$ Closely spaced strips.

Bazin gives the ratio $u / \bar{u}$ of the velocity at a point to the mean velocity in the channel for points in a horizontal section and in the midvertical section of the channel. An auxiliary computation is required to obtain the local shear velocity $u_{*}$ which enters in eq 23 . This may be obtained if the distribution of the shear velocity, that is the ratio $u_{*} / \bar{u}_{*}$, along the wall is known. The formula for this distribution is obtained by dividing each side of eq 23 by the quantity $(u / \bar{u})\left(\bar{u} / \bar{u}_{*}\right)$ which gives

$$
\frac{\bar{u}_{*}}{u_{*}}=\frac{8.5+5.75 \log \left(y / k_{s}\right)}{(u / \bar{u})\left(\bar{u} / \bar{u}_{*}\right)}
$$

By means of this relation the distribution of shear velocity in the various channels was determined. The results are given in tables 8 and 9 . They show that the shear velocity, and therefore the shear, have minimum values at the corners. On the bottom of the channel the maximum shear occurs at the midpoint. On the vertical walls the maximum shear is found at a point slightly below the water surface, and its value is considerably less than the maximum shear on the bottom. 
TABLE 9.-Distribution of shear at the sides of rough rectangular channels

$S=$ distance from bottom corner

$h=$ depth of water

$B_{0}=$ width of channel

\begin{tabular}{|c|c|c|c|c|c|}
\hline \multicolumn{2}{|c|}{$\begin{array}{l}\text { Series } 55 \text {, cement. } \\
\qquad \begin{array}{c}h / B_{0}=0.15 \\
\bar{u} / \bar{u}_{*}=24.4\end{array}\end{array}$} & \multicolumn{2}{|c|}{$\begin{array}{c}\text { Series } 56 \text {, fine gravel. } \\
h / B_{0}=0.21 \\
\bar{u} / \bar{u}_{*}=14.7\end{array}$} & \multicolumn{2}{|c|}{$\begin{array}{c}\text { Series } 57, \text { coarse. } \\
\text { gravel. } \\
h / B_{0}=0.21 \\
\bar{u} / \bar{u}_{*}=11.5\end{array}$} \\
\hline$S / h$ & $u_{*} / \bar{u}_{*}$ & $S / h$ & $u_{*} / \bar{u}_{*}$ & $S / h$ & $u_{*} / \bar{u}_{*}$ \\
\hline $\begin{array}{r}0.89 \\
.60 \\
.39 \\
.17\end{array}$ & $\begin{array}{r}0.95 \\
.95 \\
.90 \\
.87\end{array}$ & $\begin{array}{r}0.87 \\
.62 \\
.38 \\
.13\end{array}$ & $\begin{array}{r}0.91 \\
.96 \\
.90 \\
.83\end{array}$ & $\begin{array}{r}0.93 \\
.67 \\
.41 \\
.15\end{array}$ & $\begin{array}{r}0.90 \\
.94 \\
.91 \\
.72\end{array}$ \\
\hline \multicolumn{2}{|c|}{$\begin{array}{l}\text { Series } 59, \text { plank. } \\
h / B_{0}=0.13 \\
\bar{u} / \vec{u}_{*}=21.4\end{array}$} & \multicolumn{2}{|c|}{$\begin{array}{c}\text { Series } 61, \text { plank. a } \\
h / B_{0}=0.25 \\
\bar{u} / \bar{u}_{*}=17.4\end{array}$} & \multicolumn{2}{|c|}{$\begin{array}{c}\text { Series } 65 \text {, plank. b } \\
h / B_{0}=0.21 \\
\bar{u} / \bar{u}_{*}=11.5\end{array}$} \\
\hline$S / h$ & $u_{*} / \bar{u}_{*}$ & s/h & $u_{*} / \bar{u}_{*}$ & $S / h$ & $u^{*} / \bar{u}_{*}$ \\
\hline $\begin{array}{r}0.88 \\
.49 \\
.30 \\
.11\end{array}$ & $\begin{array}{r}0.97 \\
.96 \\
.92 \\
.78 \\
\end{array}$ & $\begin{array}{r}0.92 \\
.69 \\
.49 \\
.29 \\
.09\end{array}$ & $\begin{array}{r}0.92 \\
.96 \\
.93 \\
.91 \\
.79\end{array}$ & $\begin{array}{r}0.95 \\
.69 \\
.46 \\
.21 \\
.09\end{array}$ & $\begin{array}{r}0.75 \\
.91 \\
.87 \\
.75 \\
.63\end{array}$ \\
\hline
\end{tabular}

a Widely spaced strips.

b Closely spaced strips.

Now, the ratio $u / u_{*}$ may be computed from the product

$$
u / u_{*}=(u / \bar{u})\left(\bar{u}_{*} / u_{*}\right)\left(\bar{u} / \bar{u}_{*}\right),
$$

where the first factor in the product is obtained directly from Bazin's data, the second from eq 64, and the third from Bazin's data using eq 61 . The values of $u / u_{*}$ thus obtained for various channels are plotted as ordinates against the quantity $\log \left(y / k_{s}\right)$ as abscissas in figures 10 and 11 . The distribution of the points, both for the horizontal and the vertical velocity traverses, is given quite satisfactorily by the straight line representing eq 23.

\section{MAXIMUM VELOCITY IN ROUGH RECTANGULAR CHANNELS}

Bazin observed that, when the width of a channel is about five times or more the depth of water, the velocity distribution in the middle vertical is the same as in the verticals of a channel of infinite width. From measurements at the middle verticals in eight difierent channels he derived the velocity formula for wide channels in the form

$$
\frac{u_{\max }-u}{\sqrt{(h i)}}=20\left(\frac{z}{h}\right)^{2}
$$

where $u$ is the velocity at a point distant $z$ from the surface of the water and $h$ is the depth. Introducing the shear velocity $u_{*}=\sqrt{(h i g) \text {, }}$ this law can be expressed in dimensionless form as

$$
\frac{u_{\max }}{u_{*}}-\frac{u}{u_{*}}=6.3\left(\frac{z}{h}\right)^{2}
$$


It can be shown, however, that this is an approximation to the equation

$$
\frac{u_{\max }-u}{u_{*}}=5.75 \log \left(\frac{h}{h-z}\right),
$$

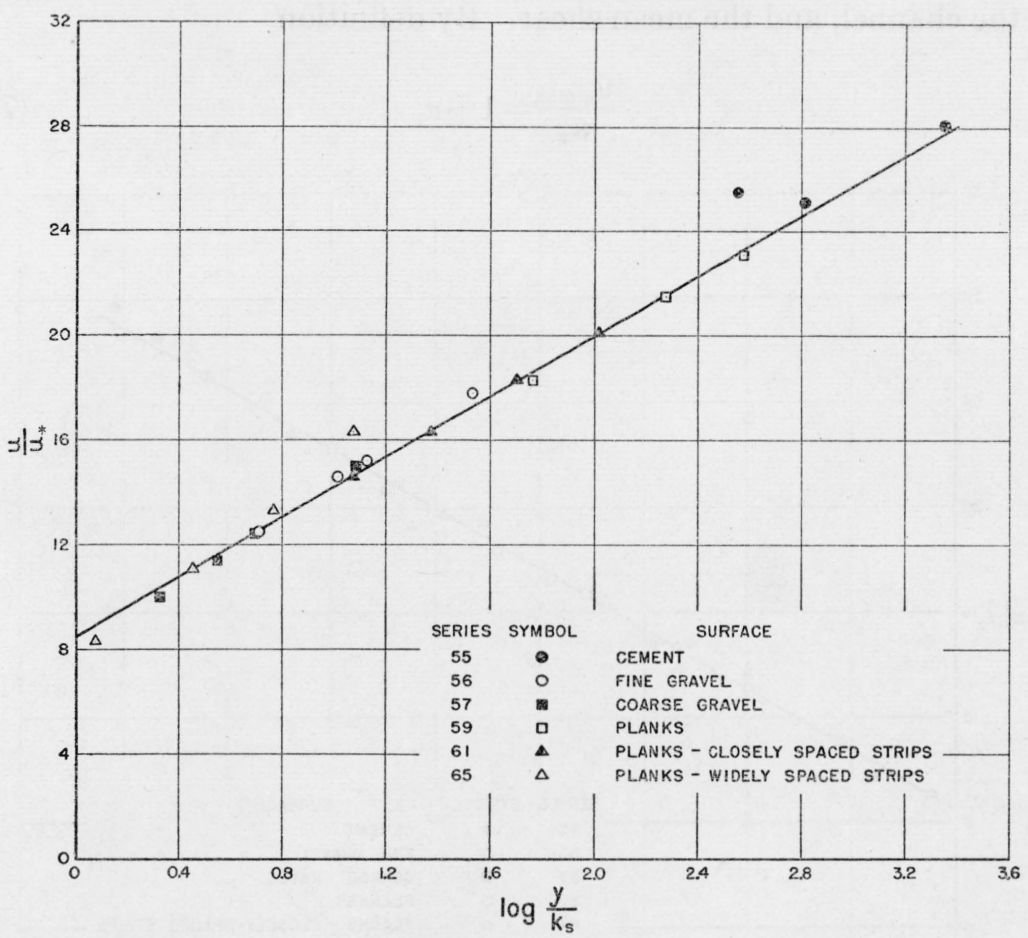

FIgURE 10.-Velocity distribution for a vertical traverse at the center line of rough rectangular channels.

The straight line represents eq 23. Basic data from Bazin.

which is deduced from the Kármán velocity law and is usually referred to as the velocity deficiency equation for the turbulent core. On the basis of eq 65 , Bazin obtained the relation between the mean velocity and the maximum velocity in very wide channels in the form

$$
u_{\max }-\bar{u}=\frac{20}{3} \sqrt{(h i)} \text {, or } u_{\max }-\bar{u}=2.13 u_{*} \text {. }
$$

In channels of finite width, on the other hand, the difference between the maximum and the mean velocity is larger, and for such cases Bazin gives on empirical grounds the relation

$$
u_{\max }-\bar{u}=14 \sqrt{(h i)} .
$$

After introducing the shear velocity, eq 69 becomes

$$
u_{\max }-\bar{u}=4.5 u_{*} .
$$


Evidently, this formula for channels of finite width lacks generality in that it does not contain the width of channel. To correct this defect the following procedure may be used if we assume that the maximum velocity occurs at the surface. First, it is necessary to find a relation between $u_{* \max }$, the maximum shear velocity at the midpoint of the channel, and the mean shear. By definition

$$
\frac{u_{* \max }}{\bar{u}_{*}}=1+\sigma,
$$

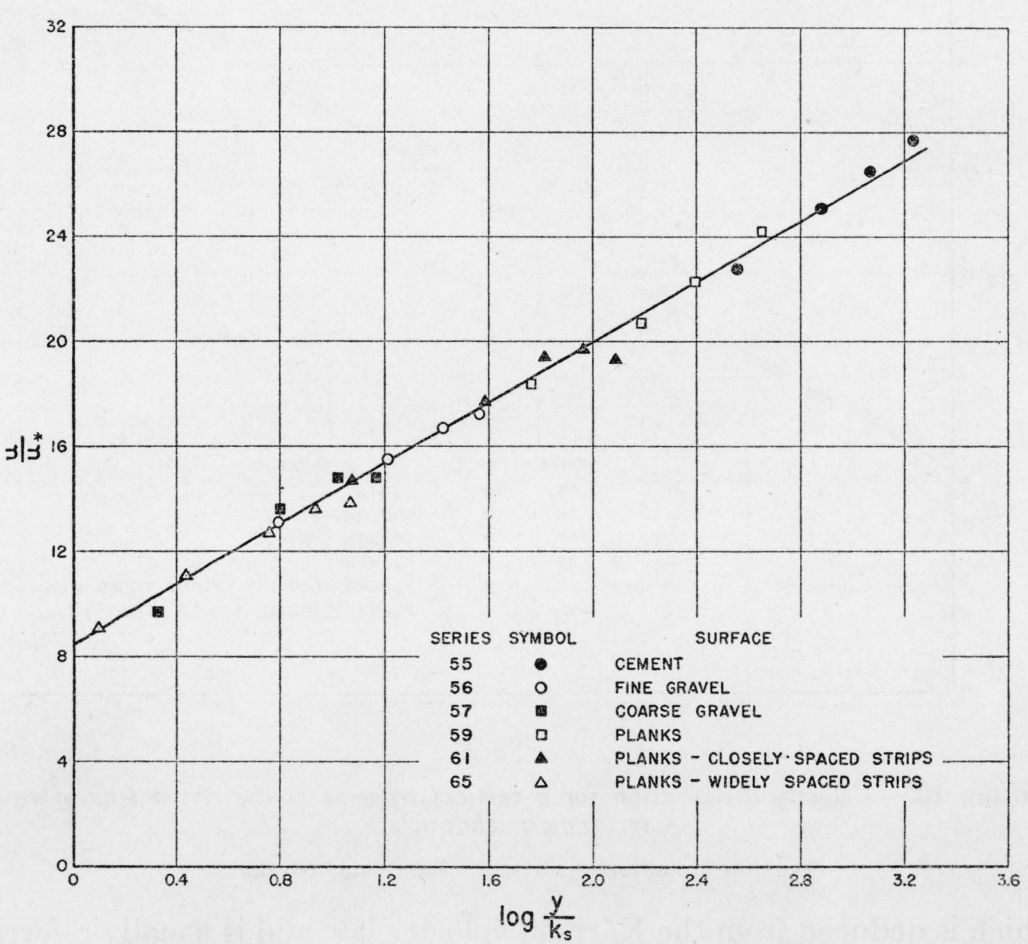

FigURE 11.-Velocity distribution for a horizontal traverse slightly below the water surface in rough rectangular channels.

The straight line represents eq 23. Basic data from Bazin.

where $\sigma$ is a function of the depth of the water, the size and roughness of the channel, and the velocity. It will be supposed that for small values of $h / B_{0}$, where $h$ is the depth and $B_{0}$ is the bottom width,

$$
\sigma=\alpha_{1} \frac{h}{B_{0}} \frac{\bar{u}_{*}}{\bar{u}}
$$

where $\alpha_{1}$ is a constant which may be determined by using some of the results of Bazin. The data to be considered are given in table 8 , and also in table 10, together with the value of $\alpha_{1}$ computed on the basis of eq 72. It is seen that $\alpha_{1}$ for different channels varies between 8.2 
and 13.2. The mean of all the determinations, 11, is perhaps a good value to adopt, since $\sigma$ is a small quantity.

The velocity law given by eq 23 and the resistance law given by eq 60 lead to

$$
\frac{u_{\max }}{u_{* \max }}-\frac{\bar{u}}{\bar{u}_{*}}=2.25+5.75 \log \left(\frac{h}{R}\right)
$$

As $h / R=1+\left(2 h / B_{0}\right)$, the logarithmic term in eq 73 can be expressed in the series form. Neglecting powers of $h / B_{0}$ higher than the second, eq 73 now becomes

or from eq 71

$$
\frac{u_{\max }}{u_{* \max }}-\frac{\bar{u}}{\bar{u}_{*}}=2.25+5 \frac{h}{B_{0}}-5\left(\frac{h}{B_{0}}\right)^{2},
$$

$$
\frac{u_{\max }-\bar{u}}{\bar{u}_{*}}=\left[2.25+5 \frac{h}{\bar{B}_{0}}-5\left(\frac{h}{\bar{B}_{0}}\right)^{2}\right](1+\sigma)+\sigma \frac{\bar{u}}{\bar{u}_{*}} .
$$

Inroducing $\sigma$ from eq 72 ,

$$
\frac{u_{\max }-\bar{u}}{\bar{u}_{*}}=2.25\left[1+C_{1} \frac{h}{B_{0}}+C_{2}\left(\frac{h}{B_{0}}\right)^{2}\right],
$$

where

$$
\begin{aligned}
& C_{1}=7.1+11 \frac{\bar{u}_{*}}{\bar{u}}, \text { and } \\
& C_{2}=24.5 \frac{\bar{u}_{*}}{\bar{u}}-2.25 .
\end{aligned}
$$

This is a formula which gives the relation of the mean velocity to the maximum velocity in rough rectangular channels where the ratio of the depth of water to the width of channel does not exceed 1:5.

TABLE 10.-Computation of the constant $\alpha$

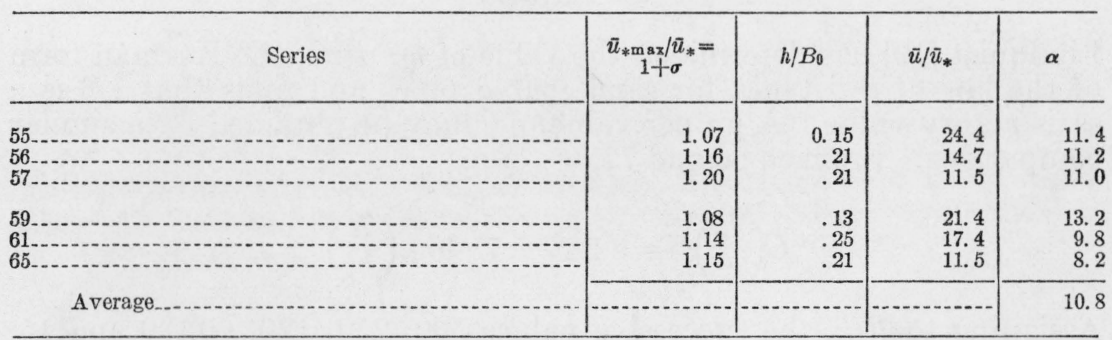

\section{MANNING'S FORMULA FOR ROUGH CHANNELS- POWER-LAW FORMULAS}

Manning's formula for mean velocity of flow in rough channels is widely used in engineering practice, mainly because of its simple form. It will be of considerable interest, therefore, to examine this formula 
in the light of the formulas which have been deduced in this paper. The formula as ordinarily written is

$$
\bar{u}=\frac{1.476}{n} R^{1 / 8} \sqrt{ }(R i),
$$

where $\bar{u}$ and $R$ are expressed in terms of feet and seconds. Introducing the acceleration of gravity, $g=32.2 \mathrm{ft} / \mathrm{sec}^{2}$, the formula becomes

$$
\bar{u}=\frac{0.263 R^{1 / 6}}{n} \sqrt{ }(R i g),
$$

or, in the notation of this paper,

$$
\frac{\bar{u}}{\bar{u}_{*}}=\frac{0.263}{n} R^{1 / 6} \text {. }
$$

The quantity $n$ is generally called "Manning's $n$," and is interpreted as a measure of roughness. Obviously, if the formula is to be dimensionally complete, the factor $0.263 / n$ must have the dimensions $[L]^{-1 / 6}$. A dimensionless formula results when the equivalent sand roughness $k_{s}$ is introduced as follows:

where

$$
\frac{\bar{u}}{\bar{u}_{*}}=C\left(R / k_{s}\right)^{1 / 6},
$$

$$
C=\frac{0.263 k_{s}^{1 / 6}}{n},\left(k_{s} \text { in } \mathrm{ft}\right) \text {, }
$$

or

$$
C=\frac{0.00863 k_{s}{ }^{1 / 6}}{n},\left(k_{s} \text { in } \mathrm{cm}\right) \text {. }
$$

Eq 77 is then a power law for the mean velocity of flow in the form

$$
\frac{\bar{u}}{\bar{u}_{*}}=C\left(\frac{R}{k_{s}}\right)^{m} \text {. }
$$

Lindquist [12] has determined the value of $m$, using the Kármán form of the law of resistance for sand-coated pipes and finds that $1 / 6$ is a satisfactory value. A proper value of $C$ may be obtained by a similar comparison. From eq 60 and 77 ,

$$
C\left(\frac{R}{k_{s}}\right)^{1 / 8}=6.25+5.75 \log \left(\frac{R}{k_{s}}\right)
$$

Assigning to $R / k_{\mathrm{s}}$ the successive values $500,250,120,60,30$ and 15 , the corresponding values of $C$ are found to be 7.72, 7.98, 8.20, 8.32, 8.36, and 8.30. Adopting for $C$ the mean value 8.12, the dimensionless form of Manning's formula will be

$$
\frac{\bar{u}}{\bar{u}_{*}}=8.12\left(\frac{R}{k_{s}}\right)^{1 / 6} .
$$


The relation between the equivalent sand roughness and Manning's $n$, according to eq 79 , now is

$$
n=0.00106 k_{g}^{1 / 6},
$$

where $k_{s}$ is expressed in centimeters. This last equation, however, is not suitable for determining the equivalent sand roughness $k_{s}$ when Manning's $n$ for a channel is known.

The value of the exponent $m$ of the power law formula is related to the roughness factor $\left(R / k_{s}\right)$. This is readily seen from a study of the velocity distribution for flows near rough surfaces. The velocities for fully developed turbulence with sand-coated surfaces are shown in figure 12 , where $\log \left(u / u_{*}\right)$ is plotted against $\log \left(y / k_{s}\right)$ in accordance with eq 23. The line thus obtained is decidedly curved, indicating

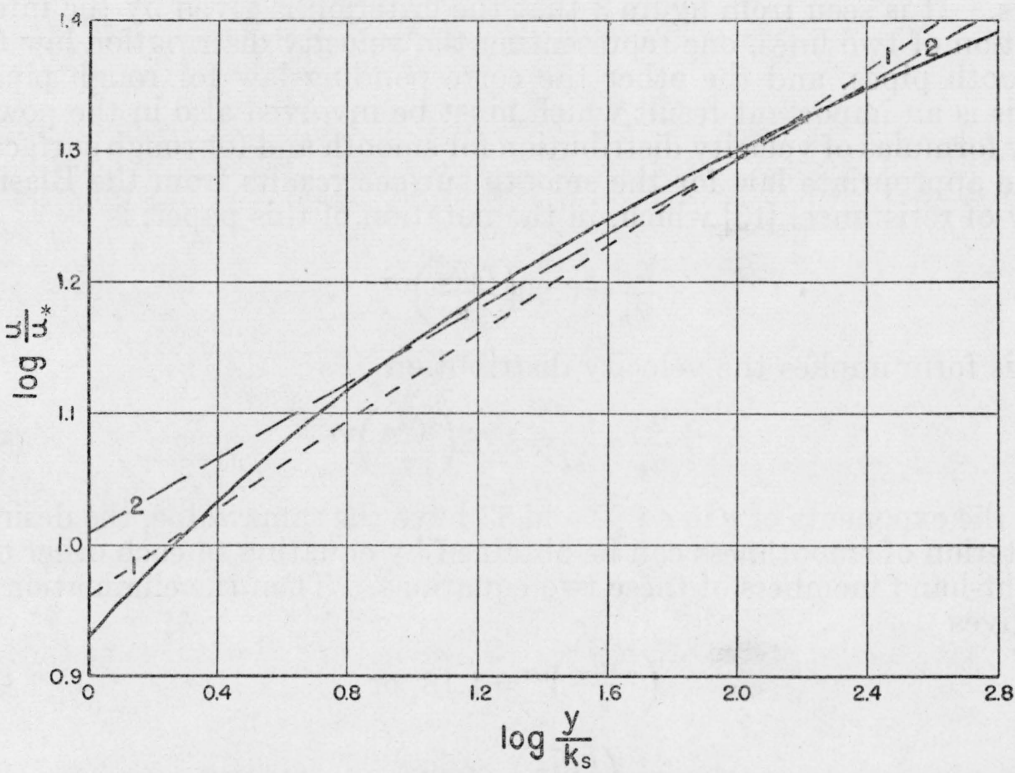

FIGURE 12.- $\log \left(u / u_{*}\right)$ as a function of $\log \left(y / k_{s}\right)$ for rough channels.

The curve represents the rational formula given by eq 23 . The line 1-1 represents the power-law formula with exponent $n=1 / 6$, which is equivalent to Manning's formula. The line $2-2$ represents the power-law formula with exponent $n=1 / 7$.

that the value of $m$ in a power law formula depends on $R / k_{s}$. If then it is desired to arrive at a mean flow formula of the power law type, it is necessary to select a straight line which will approximate the curve of eq 23 for large values of $y / k_{s}$. A practical range of $R / k_{s}$ is from $R / k_{s}=15$ to $R / k_{s}=500$. With this range in mind, two straight lines are drawn in figure 12 as fairly good approximations to actual observations. The line 1-1 represents the velocity distribution

$$
\frac{u}{u_{*}}=\frac{u}{\bar{u}_{*}}=9.15\left(\frac{y}{\bar{l}_{s}}\right)^{1 / 6} \text {, }
$$


corresponding to eq 80 . The line $2-2$ which conforms to the relation

$$
\frac{u}{u_{*}}=\frac{u}{\bar{u}_{*}}=10.2\left(\frac{y}{k_{s}}\right)^{1 / 7} \text {, }
$$

is especially useful for reasons that will now be explained.

It was mentioned earlier in the paper that the velocity distribution near a rough surface consisting of imbedded sand grains is identical wi th that near a smooth surface when the velocity of flow is sufficiently small. It is to be expected that this will be true also for roughnesses represented by cement either plain or mixed with sand, by brick, and by ashlar masonry. The departure from smoothness begins when $\bar{u}_{*} k_{s} / \nu$ reaches the value 3.3 , according to figure 3 . This number, which is of considerable interest, may be referred to as the criterion of smoothness. It is seen from figure 3 that the criterion is given by the intersection of two lines, one representing the velocity distribution law for smooth pipes, and the other the corresponding law for rough pipes. This is an important result which must be involved also in the power law formulas of velocity distribution for smooth and for rough surfaces. The appropriate law for the smooth surface results from the Blasius law of resistance, [13] which, in the notation of this paper, is

$$
\frac{\bar{u}}{\bar{u}_{*}}=6.99\left(\frac{r_{0} \bar{u}_{*}}{\nu}\right)^{1 / 7} \text {. }
$$

This form implies the velocity distribution

$$
\frac{u}{u_{*}}=\frac{u}{\bar{u}_{*}}=8.62\left(\frac{y \bar{u}_{*}}{\nu}\right)^{1 / 7} \text {. }
$$

As the exponents of $y$ in eq 82 and 83 have the same value, the desired criterion of smoothness can be obtained by equating to each other the right-hand members of these two equations. Then the elimination of $y$ gives

$$
\begin{gathered}
\left(\frac{k_{s} \bar{u}_{*}}{\nu}\right)^{1 / 7}=1.18, \text { or } \\
\left(\frac{k_{s} \bar{u}_{*}}{\nu}\right)=3.26,
\end{gathered}
$$

which is in good agreement with the value 3.3 obtained from figure 3.

It is now clear that the power law with exponent $m=1 / 7$ is sufficiently accurate when $R \bar{u}_{*} / \nu$ or $R / k_{s}$, is large, and the law with exponent $m=1 / 6$ when $R \bar{u}_{*} / \nu$ or $R / k_{s}$ is small. The formulas of the logarithmic type are free from this restriction. As a matter of possible interest, the results of Bazin's experiments on mean flow in channels will be given also in the form of power laws.

In rough channels the mean flow is given by

$$
\frac{\bar{u}}{\bar{u}_{*}}=9.1\left(\frac{R}{k_{s}}\right)^{1 / 7}, \text { or } \frac{\bar{u}}{\bar{u}_{*}}=8.12\left(\frac{R}{k_{s}}\right)^{1 / 6}
$$

The formula holds for concrete, brick, and gravel when $k_{s} \bar{u}_{*} / \nu>3.3$ and for planed wood when $k_{s} \bar{u}_{*} / \nu>42.2$. Some values of $k_{s}$ are given in table 3 . 
In smooth channels, or in rough channels with $k_{s} \bar{u}_{*} / \nu<3.3$,

$$
\frac{\bar{u}}{\bar{u}_{*}}=7.6\left(\frac{R \bar{u}_{*}}{\nu}\right)^{1 / 7} \text {. }
$$

In wooden channels with polished surfaces

$$
\frac{\bar{u}}{\bar{u}_{*}}=6.8\left(\frac{R \bar{u}_{*}}{\nu}\right)^{1 / 7} \text {. }
$$

In channels of planed wood, when $k_{s} \bar{u}_{*} / \nu<42.2$,

$$
\frac{\bar{u}}{\bar{u}_{*}}=5.2\left(\frac{R \bar{u}_{*}}{\nu}\right)^{1 / 7} \text {. }
$$

The numerical coefficients in these formulas result from the rational formula once the exponent $m=1 / 7$ is selected.

The author acknowledges gratefully the numerous suggestions and extensive editorial assistance in the preparation of this paper furnished by K. Hilding Beij of the Bureau's staff, and also helpful criticisms by Herbert N. Eaton.

\section{REFERENCES}

[1] J. Nikuradse, Gesetzmässigkeiten der turbulenten Strömung in glatten Rohren. Ver. Deut. Ing., Forschungsheft 356 (1932).

[2] J. Nikuradse, Strömungsgesetze in rauhen Rohren. Ver. Deut. Ing., Forschungsheft 361 (1933).

[3] B. A. Bakhmeteff, The Mechanics of Turbulent Flow. Princeton University Press (1936).

[4] H. Bazin, Recherches hydrauliques. Mém. divers savants, Sci. Math. et Phys., 19, Paris (1865).

[5] L. Prandtl, Ueber die ausgebildete Turbulenz. 2d Int. Congress Applied Mechanics, Zurich, p. 62 (1926).

[6] Th. v. Kármán, Mechanische Aehnlichkeit und Turbulenz. Nachr. Ges. Wiss. Göttingen, Math.-phys. Klasse, 58 (1930).

[7] H. Schlichting, Experimentelle Untersuchungen zum Rauhigkeitsproblem. Ing.-Archiv, $\boldsymbol{\%}, 1$ (1936).

[8] J. Nikuradse, Untersuchungen über turbulente Strömungen in nicht kreisformigen Rohren; Ing.-Arch. 1, 306 (1930).

[9] L. Prandtl, Zur turbulenten Strömung. Aero. Versuch. Göttingen, 4, Lief., 18 (1932).

[10] Th. v. Kármán, Über laminare und turbulente Reibung. Z. ang. Math. Mech. 1, 233 (1921).

[11] Th. v. Kármán, Turbulence and skin friction. J. Aeron. Sci. 1, 1 (1934).

[12] E. Lindquist, On velocity formulas for open channels and pipes. Special report, Third World Power Conference, Stockholm (1933).

[13] H. Blasius, Das Aehnlichkeitsgesetz bei Reibungsvorgängen in Flüssigkeiten, Ver. Deut. Ing., Forschungsheft 131 (1913).

Washington, July 13, 1938. 